\title{
Involvement of the Superior Temporal Cortex in Action Execution and Action Observation
}

\author{
Marina Kilintari, ${ }^{1,2}$ Vassilis Raos, ${ }^{1,2}$ and Helen E. Savaki ${ }^{1,2}$ \\ ${ }^{1}$ Institute of Applied and Computational Mathematics, Foundation for Research and Technology Hellas, 70013, Greece, and ${ }^{2}$ Department of Basic Sciences, \\ Faculty of Medicine, School of Health Sciences, University of Crete, 71003, Greece
}

The role of the superior temporal sulcus (STs) in action execution and action observation remains unsettled. In an attempt to shed more light on the matter, we used the quantitative method of ${ }^{14} \mathrm{C}$-deoxyglucose to reveal changes in activity, in the cortex of STs and adjacent inferior and superior temporal convexities of monkeys, elicited by reaching-to-grasp in the light or in the dark and by observation of the same action executed by an external agent. We found that observation of reaching-to-grasp activated the components of the superior temporal polysensory area [STP; including temporo-parieto-occipital association area (TPO), PGa, and IPa], the motion complex [including medial superior temporal area (MST), fundus of superior temporal area (FST), and dorsal and ventral parts of the middle temporal area (MTd and MTv, respectively)], and area TS2. A significant part of most of these activations was associated with observation of the goal-directed action, and a smaller part with the perception of arm-motion. Execution of reaching-to-grasp in the light-activated areas TS2, STP partially and marginally, and MT compared with the fixation but not to the arm-motion control. Consequently, MTactivation is associated with the arm-motion and not with the purposeful action. Finally, reaching-to-grasp in complete darkness activated all components of the motion complex. Conclusively, lack of visibility of our own actions involves the motion complex, whereas observation of others' actions engages area STP and the motion complex. Our previous and present findings together suggest that sensory effects are interweaved with motor commands in integrated action codes, and observation of an action or its execution in complete darkness triggers the retrieval of the visual representation of the action.

Key words: action execution; action observation; action representation; superior temporal cortex

\section{Introduction}

Electrophysiological studies in monkeys established that neurons in the anterior part of the superior temporal sulcus (STs) discharge when the animals observe biological stimuli, such as body and arm movements generated by an external agent (Perrett et al., 1985, 1989; Oram and Perrett, 1994; Jellema et al., 2000). Also, Rizzolatti's group suggested that STs is part of the mirror-neuron network, based on that (1) similar visual stimuli evoke responses from neurons in the STs and from mirror neurons in area F5, and (2) the STs is connected with areas containing mirror neurons (Rizzolatti et al., 2001; Rizzolatti and Craighero, 2004). However, neuroimaging studies provided conflicting results about the activations in the temporal cortex elicited by observation of fore-

Received Feb. 21, 2014; revised May 2, 2014; accepted May 29, 2014.

Author contributions: V.R. and H.E.S. designed research; M.K., V.R., and H.E.S. performed research; M.K., V.R., and H.E.S. analyzed data; M.K. and H.E.S. wrote the paper.

This work was co-financed by the European Union (European Social Fund) and the Greek State through the action "ARISTEIA II" of the Operational Programme "Education and Lifelong Learning". Marina Kilintari was supported by the Action "Supporting Postdoctoral Researchers" of the Operational Program "Education and Lifelong Learning", Action's Beneficiary: General Secretariat for Research and Technology, co-financed by the European Social Fund (ESF) and the Greek State. We thank Sophia Bakola and Mina Evangeliou for expert technical assistance and Maria Kefaloyianni for help with autoradiographic imaging.

The authors declare no competing financial interests.

Correspondence should be addressed to Helen E. Savaki, Department of Basic Sciences, Faculty of Medicine, School of Health Sciences, University of Crete, PO Box 2208, GR-71003, Iraklion, Crete, Greece. E-mail: savaki@med.uoc.gr.

DOI:10.1523/JNEUROSCI.0736-14.2014

Copyright $\odot 2014$ the authors $\quad 0270-6474 / 14 / 348999-13 \$ 15.00 / 0$ limb movements. Some studies demonstrated activations scattered over a wide area of the temporal lobe, spanning from the superior temporal gyrus (STG) to the middle temporal gyrus and inferior temporal gyrus (Iacoboni et al., 2001; Perani et al., 2001; Ohnishi et al., 2004; Shmuelof and Zohary, 2005; Grosbras and Paus, 2006; Pierno et al., 2006; Gazzola et al., 2007; Gazzola and Keysers, 2009; Turella et al., 2009; Biagi et al., 2010), whereas other studies failed to demonstrate any temporal activations for action observation (Buccino et al., 2001; Tai et al., 2004; Shmuelof and Zohary, 2006; Nedelko et al., 2010).

Even less well documented is the participation of the STs in the execution of forelimb movements. The involvement of STs in the visual control of arm movements was based on the increased activity found in area V5/hMT + for smooth tracking but not for ballistic movements of the forelimb (Oreja-Guevara et al., 2004). Similarly, the modulation of discharge of the MT neurons during tracking arm movements was associated with the visual feedback regarding the movement rather than the movement per se (Dannenberg et al., 2009). On the other hand, neuroimaging studies, investigating the action-execution and action-observation circuits, are inconclusive concerning the involvement of STs in the execution of movements. For example Oosterhof et al. (2010) reported activation in an area presumably including hMT/medial superior temporal area (MST), not only for observation, but also for execution of transitive hand movements. However the use of a static hand as control in the latter study left open the confound- 
ing possibility that the detected activation could be associated with the visual perception of the moving forelimb rather than with the execution of the purposeful hand action. Moreover, in a PET study the superior temporal cortex was found to be unaffected by execution of a purposeful forelimb-action although the moving forelimb was visible to the actor (Rizzolatti et al., 1996), whereas in a fMRI study the STG was activated for the execution of a similar action although forelimb movements were invisible to the actor (Gazzola and Keysers, 2009).

To resolve these discrepancies, we applied the high resolution, quantitative, autoradiographic ${ }^{14} \mathrm{C}$-deoxyglucose $\left({ }^{14} \mathrm{C}\right.$-DG) method to map the activity in the cortex of STs and adjacent convexities of monkeys who reached-to-grasp a $3 \mathrm{D}$ object in the light or in the dark, or who observed the same movements executed by another subject.

\section{Materials and Methods}

Subjects. Thirteen adult female monkeys (Macaca mulatta) weighing between 3 and $6 \mathrm{~kg}$ were used in the present study. They were purpose-bred by authorized suppliers within the European Union (Deutsches Primatenzentrum). Experimental protocols were approved by the institutional animal use committee, in accordance with European Union regulations concerning biosafety and the use of live animals in research (directive 2010/63/EU and its amendments) as well as with the National Institutes of Health's Principles of Laboratory Animal Care. A detailed description of surgical procedures, electromyographic activity, and eye position recordings has been reported previously (Raos et al., 2004, 2007). In brief, for head immobilization, a metal bolt was surgically implanted using mandibular plates secured by titanium screws (Synthes). Surgical procedures took place under general anesthesia using aseptic techniques. Antibiotics and analgesics were administered systemically before and after surgery, and monkeys were allowed to recover for at least 3 weeks before training commenced. Monkeys were trained to perform their tasks continuously for at least $1 \mathrm{~h}$ per day for several months before the ${ }^{14} \mathrm{C}-\mathrm{DG}$ experiment, until they perfected their performance displaying a $95 \%$ success rate. They had a water delivery tube attached close to their mouth and were rewarded for all correct responses. On the day of the ${ }^{14} \mathrm{C}-\mathrm{DG}$ experiment, monkeys performed their tasks continuously during the entire experimental period of $45 \mathrm{~min}$. Digitized electromyograms, recorded using $\mathrm{Ag}-\mathrm{AgCl}$ surface electrodes from the biceps and wrist extensor muscles (gain $\times 2000$, bandpass filter $0.3-3000 \mathrm{kHz}$ ), and eye movements, recorded with an infrared oculometer (Dr Bouis Devices), have been reported previously (Raos et al., 2004; Evangeliou et al., 2009).

Behavioral tasks. The behavioral apparatus was placed in front of the monkeys at shoulder height, $25 \mathrm{~cm}(50 \mathrm{~cm})$ away when the monkey (the experimenter) had to perform the reaching-to-grasp movement. A sliding circular window of $8^{\circ}$ diameter, at the front side of the behavioral apparatus, allowed the subject to grasp a horizontally oriented ring using the hook grip (insertion of the index finger into the ring with pronated hand). The behavioral apparatus for grasping an object has been described in detail in a previous report (Raos et al., 2004).

Two monkeys (execution of grasping in the light, EL) were trained to reach and grasp the $3 \mathrm{D}$ object (ring) with their left forelimb while their right forelimb was restricted. Each trial was initiated with the opening of the window and the illumination of the object. The monkeys had to fixate the illuminated object for $0.7-1 \mathrm{~s}$ until a dimming of the light would signal reaching, grasping, and pulling of the ring with the left forelimb while maintaining fixation. The maximum latency to grasp the object was set to $1 \mathrm{~s}$, although movement was usually completed within 500$600 \mathrm{~ms}$. EL monkeys were allowed to move their eyes outside the window only during the intertrial intervals (range, 2-2.5 s).

Three monkeys (observation of grasping, $\mathrm{O}$ ) were first trained to perform the task of the EL monkeys (grasping-training) and later on to observe the same reaching-to-grasp movements executed by the experimenter (observation-training). Although training took place months before the ${ }^{14} \mathrm{C}-\mathrm{DG}$ experiment, to cancel any possible interhemispheric differences due to earlier grasping-training, the first $\mathrm{O}$ monkey was trained to reach and grasp with its left hand, the second one with its right hand, and the third one with both hands consecutively. Accordingly, any side-to-side effect due to earlier training would be canceled out by comparing the average quantitative map of the three left hemispheres with the corresponding map of the right hemispheres. During the observationtraining and the ${ }^{14} \mathrm{C}-\mathrm{DG}$ experiment, both forelimbs of the $\mathrm{O}$ monkeys were restricted. The experimenter was always standing on the right side of the monkey and was using the right arm/hand for reaching-to-grasp. Both reaching and grasping components of the movement were visible to the monkey. The mean rate of movements was set to be similar for the execution and observation tasks.

To remove the visual effect caused by plain fixation, the activations of the temporal cortex of the EL and O groups of monkeys were compared with those of the three hemispheres of two control-fixation (Cf) monkeys. A detailed description of the behavioral apparatus for visual fixation and the behavioral tasks of Cf monkeys have been previously reported (Savaki et al., 2010; Raos et al., 2014). In brief, the behavioral apparatus was a video monitor placed in front of the monkeys. The visual targets for fixation were red circles, $1.5^{\circ}$ in diameter, and monkeys were required to maintain fixation within a circular window $2.5^{\circ}$ in diameter around the fixation target. The first monkey had to maintain fixation on a visual target straight ahead for the entire duration of the trial (4 s), and was allowed to move its eyes outside the window only during the intertrial period. Both its hemispheres were used to evaluate glucose consumption in the temporal cortex. The second monkey was required to execute an up-left saccade of $20^{\circ}$ amplitude and $135^{\circ}$ direction from the central starting position, within $0.6 \mathrm{~s}$, and to maintain fixation on each target for $0.4-0.6 \mathrm{~s}$. Intertrial intervals were between 0.3 and $0.5 \mathrm{~s}$. Since cortical areas are known to participate in the execution of contraversive saccades (Robinson and Fuchs, 1969; Bruce and Goldberg, 1985; Bakola et al., 2007), only the left hemisphere of this monkey was used in the present study. Actually, we have already demonstrated that neither the lateral intraparietal area nor the frontal eye fields are affected by ipsiversive saccades (Savaki et al., 2010, 2014).

To disambiguate the effects of the purposely reaching-to-grasp (that is, the components of reaching, hand preshaping, and object-hand interaction) from the effects of (1) non-goal-directed (purposeless) forelimb movements in front of the monkey, (2) visual stimulation due to presentation of the three-dimensional (3D) object, and (3) fixational saccades used to scan the object, we also compared the effects of the EL and O monkeys with those of two control-motion $(\mathrm{Cm})$ monkeys. Cm monkeys had no previous reaching-to-grasp training. Each $\mathrm{Cm}$ monkey had both hands restricted during the task period and was trained to maintain its gaze straight ahead (within the $8^{\circ}$ diameter circular window) during the opening of the window of the apparatus, the presentation of the illuminated object behind the opened window, the closure of the window, and while the experimenter was reaching with extended hand toward the closed window (for a total period of $2.7-3 \mathrm{~s}$ per trial). The direction of motion and the velocity of the moving arm were the same as in the observation task. The $\mathrm{Cm}$ monkeys were allowed to move their eyes outside the circular window only during the intertrial intervals (range, 2-2.5 s).

Two monkeys (execution of grasping in the dark, ED) were trained to reach and grasp with the left forelimb in complete darkness, while the right forelimb was restricted. To achieve complete darkness, the primate chair and the behavioral apparatus were enclosed within black curtains and an extra black drape was positioned in front of the monkey's eyes. A speaker, placed $25 \mathrm{~cm}$ in front of the monkeys in the median sagittal plane below the behavioral apparatus, delivered the go signals. Following a low-frequency auditory cue $(90 \mathrm{~Hz})$, each ED monkey had to look straight ahead toward the memorized location of the object for $0.7-1 \mathrm{~s}$, until a second high-frequency auditory cue $(180 \mathrm{~Hz})$ signaled the generation of the learned action (reaching, grasping, and pulling the memorized ring with the left forelimb) while maintaining its gaze straight ahead. The maximum latency to grasp the object was set to $1 \mathrm{~s}$, although the movement was usually completed within 500-600 ms. The ED monkeys were allowed to move their eyes outside the window only during the intertrial intervals (range, 2-2.5 s). 


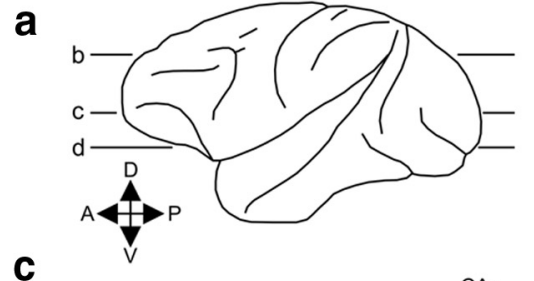

b
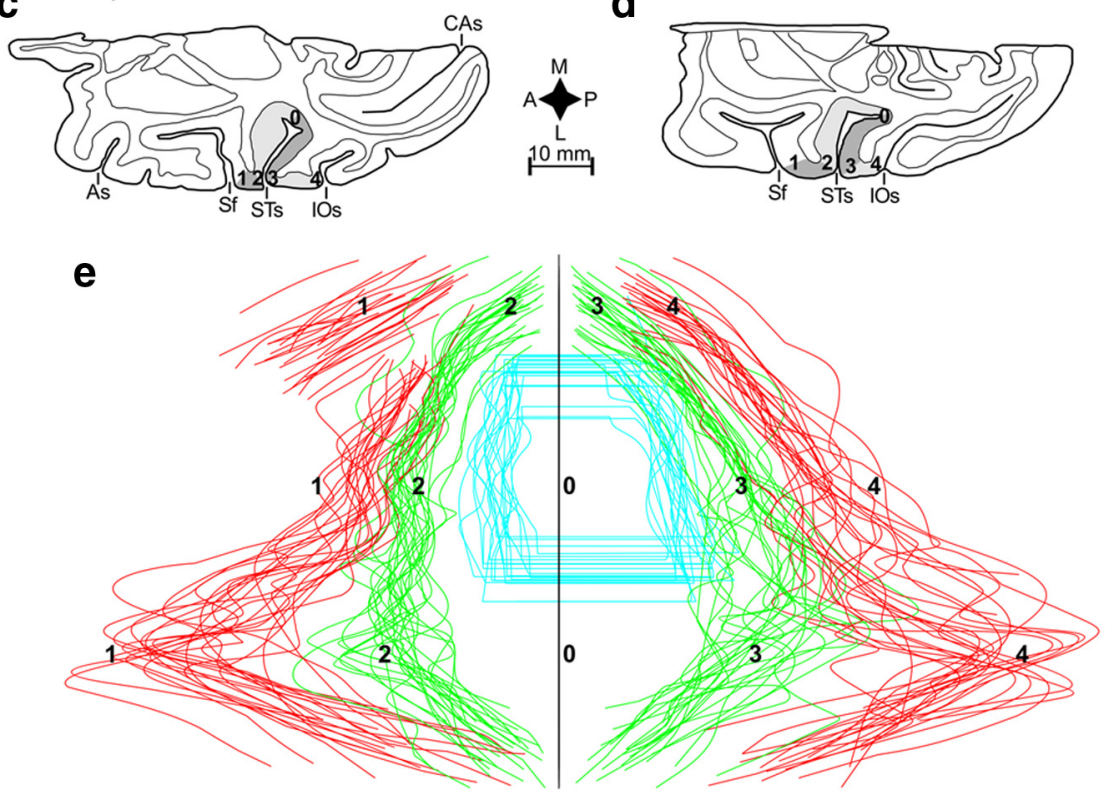

f

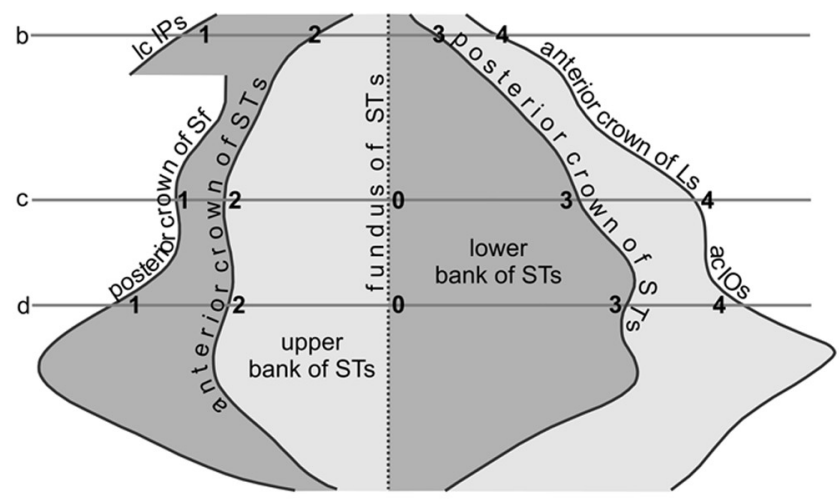

g

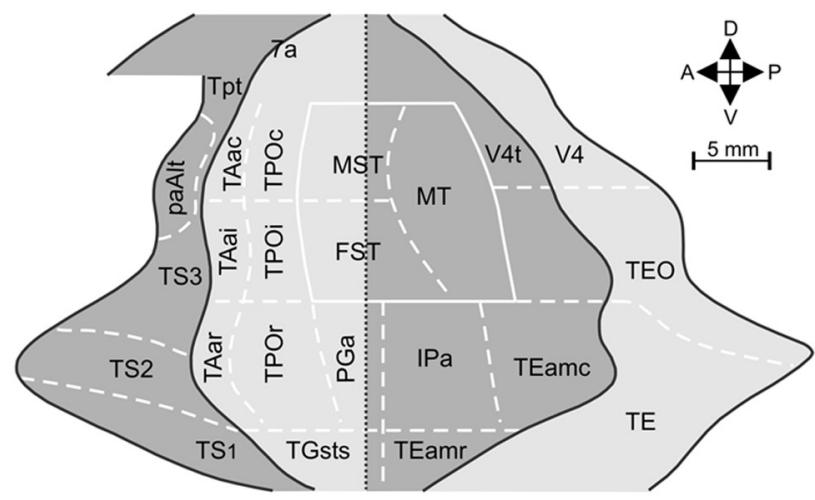

Figure 1. 2D reconstruction of the STs and adjacent convexities. $\boldsymbol{a}$, Schematic representation of the lateral view of a monkey brain indicating the dorsoventral level of three horizontal sections $(\boldsymbol{b}-\boldsymbol{d}) \cdot \boldsymbol{b}$ - $\boldsymbol{d}$, Diagrammatic representation of the three horizontal sections indicated in $\boldsymbol{a}$. Gray area (labeled $0-4$ ) indicates the temporal cortex that was flattened and reconstructed. $\boldsymbol{e}$, Outlines of the reconstructed cortical maps drawn from all of the hemispheres $(N=24)$ before geometrical normalization, aligned on the center of the vertical black line (labeled 0 ). The latter line represents the point of alignment of adjacent horizontal sections in each hemisphere, i.e., the fundus of the STs (in dorsal sections) or the posterior tip of the floor (in ventral sections), as indicated by point zero in $\boldsymbol{b}-\boldsymbol{d}$. Red lines demonstrate the endpoints of the reconstructed cortex in the superior (labeled 1) and inferior
To reveal the effects induced by reaching-tograsp in the dark, the metabolic maps of the four hemispheres from the two ED monkeys were compared with those obtained from the three hemispheres of two control-in-the-dark monkeys (Cd). The fourth hemisphere from the Cd group could not be used in the present study, due to cutting artifacts in the STs region during sectioning of the hemisphere. The $\mathrm{Cd}$ monkeys were presented with auditory stimuli similar to the acoustic cues presented to the ED monkeys. Reward was delivered at random intervals to prevent association of the auditory stimuli with the reward expectancy. The total number of rewards that the $\mathrm{Cd}$ monkeys received matched that of the ED monkeys.

${ }^{14} C-D G$ experiment and autoradiographs. The ${ }^{14} \mathrm{C}$-DG experiment and the brain tissue processing for autoradiography were performed as described previously (Savaki et al., 1993; Raos et al., 2004). In brief, 5 min after the monkeys started performing their tasks, a pulse of $100 \mathrm{mCi} / \mathrm{kg}$ of 2-deoxy-D-[1- $\left.{ }^{14} \mathrm{C}\right]$ glucose (specific activity $55 \mathrm{mCi} / \mathrm{mmol}, \mathrm{ARC}$ ) was delivered intravenously. Arterial samples were collected from the catheterized femoral artery during the succeeding $45 \mathrm{~min}$. Plasma glucose levels, blood pressure, hematocrit, and blood gases ranged within normal values in all monkeys and remained constant throughout the ${ }^{14} \mathrm{C}$-DG experiment. At the end of the experimental period, monkeys were killed by intravenous injection of sodium thiopental followed by saturated potassium chloride.

(labled 4) temporal convexities. Green lines (labeled 2 and 3) represent the borders of the upper and the lower bank (respectively) of the STs in each studied hemisphere. Blue lines illustrate the histologically identified outer borders of the motion complex. Maps from right hemispheres are reflected to match those from left hemispheres. $f$, Reference 2D map of the surface landmarks generated after geometrical normalization. Horizontal lines $\boldsymbol{b}-\boldsymbol{d}$ indicate the dorsoventral location of the sections illustrated in the corresponding panels above. Dotted vertical black line (labeled 0 ) indicates the fundus of STs (dorsally) or the posterior tip of its floor (ventrally), which was used as the point of alignment of adjacent horizontal sections. $\boldsymbol{g}$, Reference map of the surface landmarks (same as in $f$ ) and the cytoarchitectonic borders of the motion complex (solid white lines) with superimposed the anatomical borders between areas of interest in the STs and the temporal operculum (dashed white lines) drawn from the atlas of Saleem and Logothetis (2007) and the partitioning scheme of Pandya and Sanides, (1973). See Materials and Methods for the superimposition procedure, and Discussion for the nomenclature of cortical areas. A, Anterior; ac, anterior crown; As, arcuate sulcus; c, cau$\mathrm{dal}$; $C A s$, calcarine sulcus; $C \mathrm{Cs}$, cingulate sulcus; $\mathrm{Cs}$, central sulcus; D, dorsal; i, intermediate; IOs, inferior occipital sulcus; IPs, intraparietal sulcus; L, lateral; Ic, lateral crown; Ls, lunate sulcus; M, medial; MT, middle temporal (V5); P, posterior; paAlt, lateral parakoniocortex; POs, parietoccipital sulcus; $r$, rostral; Sf, Sylvian fissure; STs, superior temporal sulcus; TEO, temporo-occipital area; TEam, areas TEa and TEm; TGsts, STs region of temporal pole; TPt, temporo-parietal area; TS1, TS2, TS3, temporalis superior 1, 2, 3; V, ventral; V4, visual area 4; V4t, V4 transitional area. 
After completion of the ${ }^{14} \mathrm{C}$-DG experiment, the cerebral hemispheres were removed, frozen by immersion in isopentane at $-50^{\circ} \mathrm{C}$, covered in embedding medium to prevent dryness and stored at $-80^{\circ} \mathrm{C}$ until sectioned. Each hemisphere was cut in serial horizontal sections of $20 \mu \mathrm{m}$ thickness, using a cryostat at $-20^{\circ} \mathrm{C}$. Subsequently, the sections were exposed to medical X-ray film (EMC1, Kodak) along with a set of precalibrated ${ }^{14} \mathrm{C}$ standards (GE Healthcare). The autoradiographic films were developed in a Kodak X-OMAT 1000 automatic processor. One section every $500 \mu \mathrm{m}$ was stained with thionine for identification of cytoarchitectonic borders. Quantitative densitometric analysis of autoradiographs was performed with a computerized image processing system (MCID, Imaging Research). Local cerebral glucose utilization (LCGU) values, in $\mu \mathrm{mol} / 100 \mathrm{~g} / \mathrm{min}$, were calculated as in our previous studies (Savaki and Dalezios, 1999) by the original operational equation of the ${ }^{14} \mathrm{C}$-DG method (Sokoloff et al., 1977) using the appropriate kinetic constants for the monkey (Kennedy et al., 1978).

Reconstruction of $2 D$ quantitative maps of cortical activity. 2D reconstructions of the spatial distribution of metabolic activity within the rostrocaudal and dorsoventral extent of each hemisphere were generated as previously described (Dalezios et al., 1996; Savaki et al., 1997; Bakola et al., 2007; Raos et al., 2014). Briefly, to cover the full extent of the STs along with the temporal operculum, we used $\sim 1700$ serial horizontal sections for each hemisphere of each monkey. For each horizontal brain section, a data array was obtained by sampling LCGU values $(50 \mu \mathrm{m} /$ pixel resolution) in the rostrocaudal extent of the reconstructed temporal cortex, along a line parallel to its surface including all cortical layers (Fig. $1 b-d)$. Data arrays of five adjacent sections were averaged and plotted around the fundus of the STs sulcus (plotting resolution $100 \mu \mathrm{m}$ ) to produce one line in each reconstructed $2 \mathrm{D}$ map of activity. Figure $1 e$ illustrates maps of the outlines of the reconstructed temporal cortex, including the unfolded STs and the adjacent temporal convexities, in each studied hemisphere $(N=24)$. Specifically, the green lines (labeled 2 and 3 ) in Figure $1 e$ represent the crowns of the upper and the lower bank (respectively) of the STs in each studied hemisphere, the red lines demonstrate the endpoints of the reconstructed cortex in the superior (labeled 1) and inferior (labeled 4) temporal convexities, and the blue lines illustrate the histologically identified outer borders of the motion complex. Maps from right hemispheres are reflected to match those from left hemispheres. All these maps are aligned on the center of the vertical black line (labeled 0 ). The latter line represents the point of alignment of adjacent horizontal sections in each hemisphere, i.e., the fundus of the STs (in dorsal sections) or the posterior tip of the floor (in ventral sections), as indicated by point zero in Figure $1 b-d$. Normalization of LCGU values was based on the averaged unaffected gray matter value pooled across all monkeys, as described previously (Savaki et al., 1993; Gregoriou and Savaki, 2003).

Histology. In the present study, we were able to identify the outer borders of the motion complex in thionine-stained sections adjacent to the ones used for autoradiography. The motion complex, located in the caudal (dorsal) portion of the STs, consists of the middle temporal visual area (V5/MT) which is situated in the posterior (lower) bank (Zeki, 1974; Maunsell and Van Essen, 1983), the MST in the anterior (upper) bank, and the fundus of the superior temporal area (FST; Desimone and Ungerleider, 1986; Boussaoud et al., 1990). To identify the cytoarchitectonic borders of the motion complex in our thionine-stained sections, we used histological procedures and criteria which have been previously described (Bakola et al., 2007; Raos et al., 2014). In brief, the motion complex corresponds partially to areas OAa and PGa by Seltzer and Pandya (1978) and is characterized by the presence of a more prominent layer IV, clearly distinct from the relatively poor layer V (Seltzer and Pandya, 1978; Hof and Morrison, 1995). Ventrally in the sulcal floor, the motion complex borders area IPa (Seltzer and Pandya, 1978). OAa can be distinguished from its anteriorly neighboring area IPa by the presence of a prominent $\mathrm{VI}^{\text {th }}$ layer organized in small cell clusters in IPa.

The borders of the remaining temporal areas which could not be identified in the thionine-stained sections were demarcated using previously reported maps. The combined magnetic resonance imaging (MRI) and histology monkey atlas of Saleem and Logothetis (2007) was used for the demarcation of borders between areas MT, MST, and FST in the motion
Table 1. Conditions

\begin{tabular}{llllll}
\hline & View & & & & \\
\cline { 2 - 6 } & Fixation & 0bject & Forelimb & Hand-object interaction & Execution \\
\hline Cf & $V$ & - & - & - & - \\
$C m$ & $V$ & $V$ & $V$ & - & - \\
EL & $V$ & $V$ & $V$ & $V$ & $V$ \\
0 & $V$ & $V$ & $V$ & - & - \\
Cd & - & - & - & - & $V$ \\
ED & - & - & - & &
\end{tabular}

Table 2. Comparisons

\begin{tabular}{llll}
\hline & Cf & Cm & Cd \\
\hline EL & $V$ & $V$ & - \\
0 & $V$ & $V$ & - \\
ED & - & - & $V$ \\
\hline
\end{tabular}

complex, and between cortical areas of interest in the inferior temporal convexity and the STs (see geometrical normalization section for further details). For the delineation of borders between areas in the superior temporal gyrus we followed the partitioning scheme of Pandya and Sanides (1973), Seltzer and Pandya (1978), and Petrides and Pandya (2006).

Geometrical normalization of the 2D anatomical and functional maps of the STs. To be able to compare the activated cortical regions in the different hemispheres, despite their macroscopic-anatomical variability, the individual functional (LCGU) maps were further processed to match a reference map. The general procedure of geometrical normalization of the LCGU maps, based on surface landmarks, has been described previously (Evangeliou et al., 2009; Savaki et al., 2010; Raos et al., 2014). In the present study, the geometrical normalization of the individual 2D maps of LCGU values in both banks of the STs and the adjacent convexities was based on combined cytoarchitectonic and surface landmarks. In each autoradiographic section the surface landmarks (crowns and fundus of the STs, crowns of IPs, Sf, Ls, and IOs) were labeled (Fig. $1 b-d$, points labeled $0,1,2,3,4)$, whereas in each thionine-stained histological section both surface landmarks and cytoarchitectonically identified borders of the motion complex were marked (Fig. $1 g$, black and solid white lines, respectively). To create anatomical maps topographically matching the functional ones, the histological sections were aligned around the same point with that used for alignment of the autoradiographic sections, i.e., the fundus of the STs in dorsal sections and the posterior tip of the floor of the STs in ventral sections.

The reference map for the geometrical normalization is that used in Raos et al. (2014). To generate it, we first resampled along the dorsoventral dimension using linear interpolation, so that in all maps the dorsoventral lengths of a dorsal (and a ventral) part bordered by the ventral boundary of area FST were equal to the corresponding average dorsoventral extent of each map. Then, we normalized along the anteroposterior dimension so that the relative position of the surface landmarks (crowns and fundus of the STs) and the cytoarchitectonic borders of the motion complex was the same in all maps. The specific process was as follows: we measured the section-by-section distances between (i) the lateral crown of the IPs (for the dorsalmost sections) or the posterior crown of the Sf (for more ventral sections) and the anterior crown of the STs, (ii) the latter and the anterior cytoarchitectonic border of the motion complex (areas MST, FST), (iii) the latter and the fundus or the posterior tip of the floor of the STs (point of alignment), (iv) the latter and the posterior cytoarchitectonic border of the motion complex (area MT), (v) the latter and the posterior crown of the STs, and (vi) the latter and the anterior crown of either the lunate sulcus (Ls, for dorsal sections) or the inferior occipital sulcus (IOs, for ventral sections) (Fig. 1f,g). The average of each one of these measures/distances was estimated to produce a reference map (Raos et al., 2014) of the surface landmarks and the cytoarchitectonic borders of the motion complex (Fig. 1g, black and solid white lines). Subsequently, each individual cortical map from the 24 hemispheres used in the present study with its own landmarks was linearly 
Table 3. Metabolic effects of reaching-to-grasp in the light

\begin{tabular}{|c|c|c|c|c|c|c|c|c|c|c|}
\hline Cortical area & $n$ & $\begin{array}{c}\text { Cf } \\
(\mathrm{LCGU} \pm \mathrm{SD})\end{array}$ & $\begin{array}{c}\mathrm{Cmi} \\
(\mathrm{LCGU} \pm \mathrm{SD})\end{array}$ & $\begin{array}{c}\mathrm{CmC} \\
(\mathrm{LCGU} \pm \mathrm{SD})\end{array}$ & $\begin{array}{c}\text { Eli } \\
(\mathrm{LCGU} \pm \mathrm{SD})\end{array}$ & $\begin{array}{c}\mathrm{ELi} / \mathrm{Cf} \\
(\%)\end{array}$ & $\begin{array}{l}\text { ELi/Cmi } \\
(\%)\end{array}$ & $\begin{array}{c}\mathrm{ELC} \\
(\mathrm{LCGU} \pm \mathrm{SD})\end{array}$ & $\begin{array}{c}\text { ELc/Df } \\
(\%)\end{array}$ & $\begin{array}{c}\mathrm{ELc} / \mathrm{Cmc} \\
(\%)\end{array}$ \\
\hline MST & 63 & $52.3 \pm 1.3$ & $56.1 \pm 0.9$ & $58.5 \pm 1.1$ & $55.6 \pm 1.3$ & 6.3 & -0.9 & $55.6 \pm 2.3$ & 6.3 & -5.0 \\
\hline FST & 75 & $52.2 \pm 1.5$ & $53.1 \pm 1.9$ & $58.9 \pm 2.3$ & $53.8 \pm 1.4$ & 3.1 & 1.3 & $54.9 \pm 1.7$ & 5.2 & -6.8 \\
\hline MTd & 63 & $56.5 \pm 0.6$ & $59.3 \pm 0.8$ & $61.9 \pm 0.6$ & $62.1 \pm 1.3$ & 9.9 & 4.7 & $61.9 \pm 0.8$ & 9.6 & 0.0 \\
\hline MTV & 75 & $54.9 \pm 0.9$ & $64.0 \pm 1.3$ & $65.7 \pm 0.8$ & $60.2 \pm 0.6$ & 9.7 & -5.9 & $61.8 \pm 0.9$ & 12.6 & -5.9 \\
\hline Tpt & 71 & $44.2 \pm 2.3$ & $48.1 \pm 0.7$ & $47.4 \pm 0.6$ & $47.0 \pm 1.0$ & 6.3 & -2.3 & $46.5 \pm 0.7$ & 5.2 & -1.9 \\
\hline paAlt & 84 & $66.4 \pm 2.1$ & $63.0 \pm 2.3$ & $59.4 \pm 2.0$ & $61.8 \pm 1.5$ & -6.9 & -1.9 & $63.0 \pm 1.3$ & -5.1 & 6.1 \\
\hline TS3 & 109 & $59.8 \pm 1.6$ & $57.2 \pm 2.0$ & $58.5 \pm 2.4$ & $59.6 \pm 1.6$ & -0.3 & 4.2 & $61.7 \pm 1.2$ & 3.2 & 5.5 \\
\hline TS2 & 73 & $48.3 \pm 0.8$ & $47.1 \pm 0.6$ & $50.8 \pm 0.9$ & $55.6 \pm 0.6$ & 15.1 & 18.0 & $54.8 \pm 1.4$ & 13.5 & 7.9 \\
\hline TS1 & 94 & $38.1 \pm 1.3$ & $37.4 \pm 1.1$ & $38.9 \pm 1.1$ & $39.4 \pm 1.8$ & 3.4 & 5.3 & $35.5 \pm 1.6$ & -6.8 & -8.7 \\
\hline TAac & 63 & $44.5 \pm 0.5$ & $48.5 \pm 1.0$ & $48.5 \pm 0.8$ & $47.9 \pm 1.1$ & 7.6 & -1.2 & $47.2 \pm 1.8$ & 6.1 & -2.7 \\
\hline TAai & 75 & $58.5 \pm 0.6$ & $55.0 \pm 1.4$ & $55.6 \pm 1.0$ & $57.2 \pm 0.4$ & -2.2 & 4.0 & $60.5 \pm 0.8$ & 3.4 & 8.8 \\
\hline TAar & 90 & $50.7 \pm 1.3$ & $49.6 \pm 1.5$ & $50.5 \pm 1.5$ & $54.1 \pm 1.6$ & 6.7 & 9.1 & $54.9 \pm 1.1$ & 8.3 & 8.7 \\
\hline TPOC & 63 & $46.2 \pm 0.8$ & $48.6 \pm 0.5$ & $52.2 \pm 1.0$ & $48.1 \pm 1.0$ & 4.1 & -1.0 & $47.6 \pm 1.1$ & 3.0 & -8.8 \\
\hline TPOi & 75 & $49.1 \pm 0.9$ & $50.1 \pm 0.8$ & $51.5 \pm 0.8$ & $49.2 \pm 1.3$ & 0.2 & -1.8 & $53.4 \pm 1.5$ & 8.8 & 3.7 \\
\hline TPOr & 35 & $46.3 \pm 0.3$ & $45.4 \pm 1.5$ & $45.3 \pm 0.8$ & $48.9 \pm 0.7$ & 5.6 & 7.7 & $49.9 \pm 0.7$ & 7.8 & 10.2 \\
\hline PGa & 53 & $48.5 \pm 0.4$ & $48.2 \pm 0.9$ & $49.7 \pm 0.7$ & $54.1 \pm 1.4$ & 11.5 & 12.2 & $48.4 \pm 0.7$ & -0.2 & -2.6 \\
\hline $\mathrm{IPa}$ & 44 & $51.0 \pm 1.2$ & $53.2 \pm 1.6$ & $55.5 \pm 0.8$ & $52.2 \pm 0.7$ & 2.4 & -1.9 & $51.7 \pm 1.9$ & 1.4 & -6.8 \\
\hline TGsts & 40 & $43.7 \pm 0.7$ & $43.6 \pm 0.3$ & $43.7 \pm 0.3$ & $43.6 \pm 0.8$ & -0.2 & 0.0 & $42.0 \pm 0.9$ & -3.9 & -3.9 \\
\hline V4 & 80 & $54.0 \pm 0.7$ & $56.6 \pm 1.1$ & $53.9 \pm 1.0$ & $56.1 \pm 1.0$ & 3.9 & -0.9 & $55.8 \pm 0.9$ & 3.3 & 3.5 \\
\hline V4t & 80 & $56.3 \pm 0.7$ & $56.8 \pm 0.7$ & $57.1 \pm 1.1$ & $55.5 \pm 1.1$ & -1.4 & -2.3 & $57.6 \pm 0.9$ & 2.3 & 0.9 \\
\hline TEO & 129 & $54.6 \pm 0.7$ & $62.3 \pm 1.1$ & $60.1 \pm 1.4$ & $53.9 \pm 1.1$ & -1.3 & -13.5 & $55.0 \pm 1.4$ & 0.7 & -8.5 \\
\hline TE & 141 & $55.5 \pm 1.2$ & $56.7 \pm 1.2$ & $55.7 \pm 1.3$ & $50.4 \pm 1.3$ & -9.2 & -11.1 & $51.5 \pm 1.0$ & -7.2 & -7.5 \\
\hline TEamc & 91 & $55.2 \pm 0.7$ & $57.0 \pm 0.6$ & $58.1 \pm 0.9$ & $53.7 \pm 0.7$ & -2.7 & -5.8 & $54.1 \pm 0.9$ & -2.0 & -6.9 \\
\hline TEamr & 40 & $51.0 \pm 0.6$ & $49.5 \pm 0.3$ & $49.5 \pm 0.3$ & $45.0 \pm 0.9$ & -11.8 & -9.1 & $43.3 \pm 0.6$ & -15.1 & -12.5 \\
\hline
\end{tabular}

$\mathrm{LCGU}$ values (mean \pm SD in $\mu \mathrm{mol} / 100 \mathrm{~g} / \mathrm{min}$ ) in temporal cortical areas of the monkey brain for execution of reaching-to-grasp in the light (EL). $n$ indicates the number of sets of five adjacent horizontal sections used to obtain the mean LCGU values for each region. (f values represent the average LCGU values from the three control hemispheres of the control-fixation monkeys. (mi (Cmc) values represent the average LCGU values from the two ipsilateral (contralateral) hemispheres of the control-motion monkeys. ELi (ELc) values represent the average LCGU values from the two hemispheres of the EL monkeys ipsilateral (contralateral) to the moving forelimb. ELi/(f\% (ELc/Cf\%), percentage differences between the ELi (ELc) and the (f, calculated as [experimental (ipsilateral or contralateral) - control]/control $\times 100$. ELi/Cmi\% (ELc/Cmc\%), percentage differences between the ELi (ELc) and the ( $\mathrm{mi}$ (Cmc), respectively. Boldface values indicate statistically significant differences by one-way ANOVA $(p<0.01$ ) followed by Dunnett's post hoc test to correct for multiple pairwise comparisons with the control monkeys. $c$, caudal (when referring to areas) or contralateral (when referring to hemispheres); d, dorsal; FST, floor of superior temporal; i, intermediate (when referring to areas) or ispilateral (when referring to hemispheres); MT, middle temporal (V5); MST, medial superior temporal; paAlt, lateral parakoniocortex; r, rostral; TE0, temporo-occipital area; TEam: areas TEa and TEm; TGsts, STs region of temporal pole; TP0, temporo-parieto-occipital association area in STs; TPt, temporo-parietal area; TS1, TS2, TS3, temporalis superior 1 , 2,$3 ; \mathrm{v}$, ventral; V4, visual area 4; V4t, V4 transitional area.

transformed (Moschovakis et al., 2004) with the help of custom-built routines in the Matlab environment (MathWorks, Natick, MA) to match the reference map. The geometrically normalized maps were combined to obtain average LCGU maps of the control and experimental groups, and to subtract the average maps of the control groups from the experimental ones. In specific, to generate an average map, the LCGU value found in a certain pixel in one of the geometrically normalized maps was added to the value found in the pixel occupying the same position in one or more other similar maps, and the result was divided by the number of maps used. Similarly, to generate a difference map, the LCGU value found in a certain pixel of a geometrically normalized map of a control hemisphere was subtracted from the value found in the pixel occupying the same position in a similar map obtained from an experimental hemisphere. With this procedure, although the total surface of an area may change when it is geometrically normalized, the intensity and the spatial distribution of LCGU effects are preserved within it because these effects are proportionally shrunk or expanded within its borders.

Similarly, based on corresponding distances in horizontal sections obtained from the atlas of Saleem and Logothetis (2007), we generated a geometrically normalized anatomical map which included the borders between all temporal cortical areas. The latter map was used to delineate in our reference map the anatomical borders between areas of interest in the STs and the inferior temporal operculum, (Fig. $1 g$, dashed white lines). For the demarcation of borders between areas in the superior temporal gyrus we used the partitioning scheme of Pandya and Sanides (1973). Superimposition of each geometrically normalized functional (LCGU) map on top of the corresponding histological map (based on thionine-sections), and of both of them on top of the anatomical map (based on the atlas) allowed for the precise localization of the activations within specific temporal cortical areas.

Statistical analysis. Tables 1 and 2 demonstrate all the conditions we examined along with the behavioral parameters involved in each one of them, as well as the comparisons we made among them. We generated Cf,
$\mathrm{Cd}$, and $\mathrm{Cm}$ maps by averaging the geometrically normalized glucograms (individual maps of the distribution of metabolic activity) from the three hemispheres of the control-fixation monkeys, the three hemispheres of the control-in-the-dark monkeys, and the four hemispheres of the control-motion monkeys, respectively. In addition, we generated EL, $\mathrm{O}$, and ED maps by averaging the geometrically normalized glucograms separately from the hemispheres contralateral and ipsilateral to the moving arm. The averaged glucograms were used for measurement of LCGU values in the cortical areas of interest in each group, and for statistical comparison of each experimental with its corresponding control group (Tables 3-5). The percentage LCGU differences between averaged experimental and control groups were calculated using the formula (experimental-control)/control $\times 100$. The hemispheres contralateral (c) and ipsilateral (i) to the moving arm in the experimental groups were considered separately. The statistical significance of differences in LCGU values was determined by one-way ANOVA $(p<0.01)$ followed by Dunnett's post hoc test to correct for multiple pairwise comparisons with the control monkeys. Adopting a conservative criterion, only differences exceeding $7 \%$ were considered for statistical analysis given that LCGU values of homonymous areas in opposite hemispheres of a normal resting monkey can differ by up to 7\% (Kennedy et al., 1978; Savaki et al., 1993, 2010).

\section{Results}

The oculomotor behavior of the monkeys used in the present study was reported in a previous paper (Kilintari et al., 2011). In brief, all monkeys, except for the Cd ones, maintained their line of sight within the window of the behavioral apparatus $\left(8^{\circ}\right.$ in diameter) for at least $7 \mathrm{~min}$ during the first $10 \mathrm{~min}$ of the ${ }^{14} \mathrm{C}$-DG experiment. This period of time is critical because $>85 \%$ of the radiolabeled DG is taken up before it ends (Sokoloff et al., 1977). During the nonfixating intervals, the line of sight of all experi- 

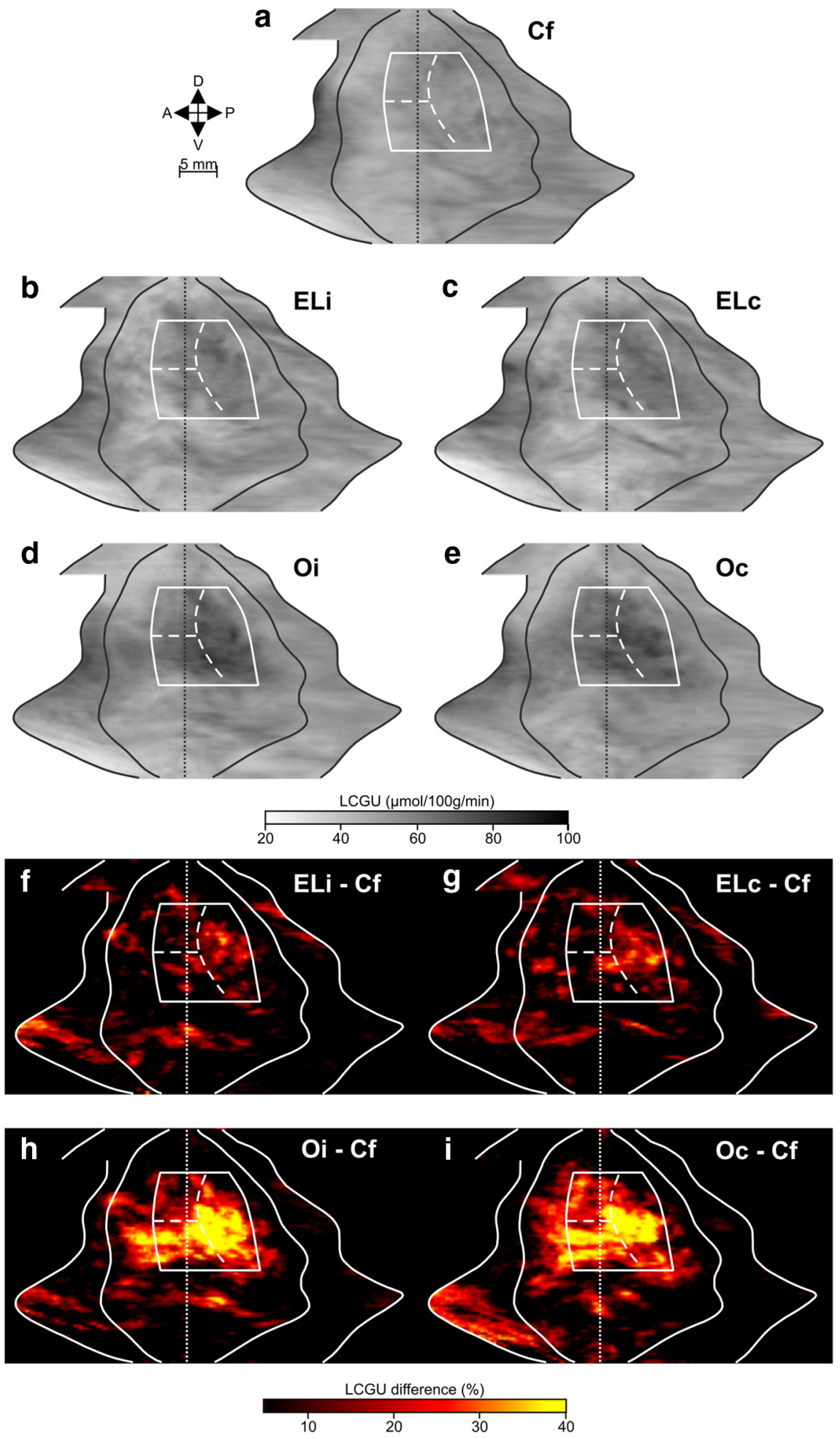

Figure 2. Quantitative 2D maps of activity in the temporal cortex of monkeys reaching-to-grasp in the light and monkeys observing the same movements executed by the experimenter. $\boldsymbol{a}$, Quantitative $2 \mathrm{D}$ map of metabolic activity obtained after averaging the LCGU values, pixel by pixel, in the geometrically normalized maps of the three hemispheres of the C $f$ monkeys. Solid white lines represent the cytoarchitectonically identified borders of the motion complex. Dotted black line, STs-fundus (dorsally) or the posterior tip of its floor (ventrally); inner solid black lines, STs-crowns; outer solid black lines, endpoints of the reconstructed cortex in the superior and inferior temporal convexities; dashed white lines, borders of areas MT, MST, and FST from atlases according to Figure $1 \mathrm{~g} . \boldsymbol{b}, 2 \mathrm{D}$ map of activity obtained after averaging the geometrically normalized maps of the two hemispheres ipsilateral to the moving forelimb, in the two monkeys executing reaching-to-grasp movements in the light (ELi). c, 2D map of activity obtained after averaging the geometrically normalized maps of the two hemispheres contralateral to the moving forelimb, in the two EL monkeys (ELC). $\boldsymbol{d}$, Quantitative 2D map of metabolic activity obtained after averaging the LCGU values in the normalized maps of the three hemispheres, ipsilaterally to the perceived moving arm, in the three monkeys observing reaching- mental monkeys was at random positions in the oculomotor space. In other words, the animals did not display any systematic oculomotor behavior that could account for false-positive effects in oculomotor related areas. The $\mathrm{Cd}$ monkeys displayed an approximately even distribution of eye positions in the oculomotor space. To control for possible rate-related effects, the mean frequency of forelimb movements was set to be similar for all behavioral tasks. During the first $10 \mathrm{~min}$, the EL and the ED monkeys executed an average of 10 and 11 reaching-to-grasp movements per minute respectively, the O monkeys observed an average of 12 reaching-to-grasp movements per minute, and the Cm monkeys an average of 12 non-goal-directed forelimb movements per minute.

To reveal the temporal areas which were specifically affected by the EL, ED and $\mathrm{O}$ tasks, we generated quantitative 2D maps of the spatio-intensive distribution of metabolic activity (glucograms, in $\mu \mathrm{mol} / 100 \mathrm{~g} / \mathrm{min}$ of glucose consumption) in the STs and adjacent convexities, as analytically described in Materials and Methods (Fig. 1), and we compared them with the corresponding control maps. Figure $2 a$ illustrates the averaged glucogram obtained from the three Cf hemispheres. Figure $2 b, c$ depicts the averaged metabolic maps of the two hemispheres ipsilaterally (ELi) and the two hemispheres contralaterally (ELc) to the moving forelimb of the EL monkeys, respectively. Figure $2 d$, e illustrates the averaged glucograms in the hemispheres of the $\mathrm{O}$ monkeys, ipsilaterally (Oi) and contralaterally (Oc) to the moving arm of the experimenter, respectively. When the quantitative averaged maps of the temporal cortex in the ipsilateral and contralateral hemispheres of the EL monkeys were compared with the averaged Cf-map, significant bilateral activations were measured in the dorsal and ventral parts of the motion-sensitive area

to-grasp movements (0i).e, 2D map of activity obtained after averaging the geometrically normalized maps of the three hemispheres contralateral to the perceived moving arm, in the 0 monkeys (0c). Grayscale indicates glucose consumption (LCGU values) in $\mu \mathrm{mol} / 100 \mathrm{~g} / \mathrm{min} . \boldsymbol{f}, \boldsymbol{g}$, Quantitative 2D maps of net activations for action execution in the light, generated after subtracting the average (f map (shown in $\boldsymbol{a}$ ) from the average Eli and ELc maps (shown in $\boldsymbol{b}$ and c, respectively) and expressed as percentage LCGU difference. White lines correspond to surface landmarks and cytoarchitectonic borders. $\boldsymbol{h}, \boldsymbol{i}$, Quantitative 2D maps of net activations for action observation, generated after subtracting the average (f map from the average $0 \mathrm{i}$ and $\mathrm{Oc}$ maps (shown in $\boldsymbol{d}$ and $\boldsymbol{e}$, respectively). Color bar indicates percentage LCGU difference from the (f monkey. 
Table 4. Metabolic effects of observation of reaching-to-grasp

\begin{tabular}{|c|c|c|c|c|c|c|c|c|c|c|}
\hline Cortical area & $n$ & $\begin{array}{c}\text { Cf } \\
(L C G U \pm S D)\end{array}$ & $\begin{array}{c}\text { Cmi } \\
(\mathrm{LCGU} \pm \mathrm{SD})\end{array}$ & $\begin{array}{c}\mathrm{CmC} \\
(\mathrm{LCGU} \pm \mathrm{SD})\end{array}$ & $\begin{array}{c}0 \mathrm{i} \\
(\mathrm{LCGU} \pm \mathrm{SD})\end{array}$ & $\begin{array}{l}0 \mathrm{i} / \mathrm{Cf} \\
(\%)\end{array}$ & $\begin{array}{l}0 \mathrm{i} / \mathrm{Cmi} \\
(\%)\end{array}$ & $\begin{array}{c}O C \\
(L C G U \pm S D)\end{array}$ & $\begin{array}{c}0 \mathrm{C} / \mathrm{Cf} \\
(\%)\end{array}$ & $\begin{array}{c}0 \mathrm{c} / \mathrm{Cmc} \\
(\%)\end{array}$ \\
\hline MST & 63 & $52.3 \pm 1.3$ & $56.1 \pm 0.9$ & $58.5 \pm 1.1$ & $60.6 \pm 1.4$ & 15.9 & 8.0 & $64.5 \pm 0.9$ & 23.3 & 10.3 \\
\hline FST & 75 & $52.2 \pm 1.5$ & $53.1 \pm 1.9$ & $58.9 \pm 2.3$ & $65.9 \pm 1.1$ & 26.2 & 24.1 & $66.7 \pm 1.3$ & 27.8 & 13.2 \\
\hline MTd & 63 & $56.5 \pm 0.6$ & $59.3 \pm 0.8$ & $61.9 \pm 0.6$ & $67.1 \pm 1.3$ & 18.8 & 13.2 & $65.3 \pm 1.1$ & 15.6 & 5.5 \\
\hline MTV & 75 & $54.9 \pm 0.9$ & $64.0 \pm 1.3$ & $65.7 \pm 0.8$ & $72.8 \pm 1.1$ & 32.6 & 13.8 & $71.0 \pm 0.9$ & 29.3 & 8.1 \\
\hline Tpt & 71 & $44.2 \pm 2.3$ & $48.1 \pm 0.7$ & $47.4 \pm 0.6$ & $47.0 \pm 0.7$ & 6.3 & -2.3 & $44.2 \pm 0.7$ & 0.0 & -6.8 \\
\hline paAlt & 84 & $66.4 \pm 2.1$ & $63.0 \pm 2.3$ & $59.4 \pm 2.0$ & $67.4 \pm 0.8$ & 1.5 & 7.0 & $62.5 \pm 1.1$ & -5.9 & 5.2 \\
\hline TS3 & 109 & $59.8 \pm 1.6$ & $57.2 \pm 2.0$ & $58.5 \pm 2.4$ & $61.0 \pm 0.9$ & 2.0 & 6.6 & $60.1 \pm 1.5$ & 0.5 & 2.7 \\
\hline TS2 & 73 & $48.3 \pm 0.8$ & $47.1 \pm 0.6$ & $50.8 \pm 0.9$ & $53.0 \pm 1.1$ & 9.7 & 12.5 & $57.1 \pm 0.9$ & 18.2 & 12.4 \\
\hline TS1 & 94 & $38.1 \pm 1.3$ & $37.4 \pm 1.1$ & $38.9 \pm 1.1$ & $37.6 \pm 1.3$ & -1.3 & 0.5 & $44.7 \pm 1.8$ & 17.3 & 14.9 \\
\hline ТАас & 63 & $44.5 \pm 0.5$ & $48.5 \pm 1.0$ & $48.5 \pm 0.8$ & $49.6 \pm 0.7$ & 11.5 & 2.3 & $47.5 \pm 1.0$ & 6.7 & -2.1 \\
\hline TAai & 75 & $58.5 \pm 0.6$ & $55.0 \pm 1.4$ & $55.6 \pm 1.0$ & $61.9 \pm 0.8$ & 5.8 & 12.5 & $60.3 \pm 0.5$ & 3.1 & 8.5 \\
\hline TAar & 90 & $50.7 \pm 1.3$ & $49.6 \pm 1.5$ & $50.5 \pm 1.5$ & $53.6 \pm 0.9$ & 5.7 & 8.1 & $52.7 \pm 0.6$ & 3.9 & 4.4 \\
\hline TPOC & 63 & $46.2 \pm 0.8$ & $48.6 \pm 0.5$ & $52.2 \pm 1.0$ & $50.1 \pm 0.9$ & 8.4 & 3.1 & $54.2 \pm 0.8$ & 17.3 & 3.8 \\
\hline TPOi & 75 & $49.1 \pm 0.9$ & $50.1 \pm 0.8$ & $51.5 \pm 0.8$ & $60.9 \pm 0.9$ & 24.0 & 21.6 & $60.4 \pm 0.6$ & 23.0 & 17.3 \\
\hline TPOr & 35 & $46.3 \pm 0.3$ & $45.4 \pm 1.5$ & $45.3 \pm 0.8$ & $51.1 \pm 0.9$ & 10.4 & 12.6 & $52.0 \pm 1.1$ & 12.3 & 14.8 \\
\hline PGa & 53 & $48.5 \pm 0.4$ & $48.2 \pm 0.9$ & $49.7 \pm 0.7$ & $52.4 \pm 1.0$ & 8.0 & 8.7 & $55.5 \pm 1.9$ & 14.4 & 11.7 \\
\hline $\mathrm{IPa}$ & 44 & $51.0 \pm 1.2$ & $53.2 \pm 1.6$ & $55.5 \pm 0.8$ & $57.9 \pm 1.4$ & 13.5 & 8.8 & $55.1 \pm 1.4$ & 8.0 & -0.7 \\
\hline TGsts & 40 & $43.7 \pm 0.7$ & $43.6 \pm 0.3$ & $43.7 \pm 0.3$ & $42.4 \pm 0.8$ & -3.0 & -2.8 & $47.0 \pm 0.6$ & 7.6 & 7.6 \\
\hline V4 & 80 & $54.0 \pm 0.7$ & $56.6 \pm 1.1$ & $53.9 \pm 1.0$ & $55.0 \pm 0.8$ & 1.9 & -2.8 & $52.0 \pm 0.6$ & -3.7 & -3.5 \\
\hline V4t & 80 & $56.3 \pm 0.7$ & $56.8 \pm 0.7$ & $57.1 \pm 1.1$ & $55.3 \pm 1.5$ & -1.8 & -2.6 & $55.1 \pm 1.0$ & -2.1 & -3.5 \\
\hline TEO & 129 & $54.6 \pm 0.7$ & $62.3 \pm 1.1$ & $60.1 \pm 1.4$ & $55.3 \pm 1.8$ & 1.3 & -11.2 & $53.6 \pm 2.2$ & -1.8 & -10.8 \\
\hline TE & 141 & $55.5 \pm 1.2$ & $56.7 \pm 1.2$ & $55.7 \pm 1.3$ & $48.9 \pm 1.4$ & -11.9 & -13.8 & $49.5 \pm 1.0$ & -10.8 & -11.1 \\
\hline TEamc & 91 & $55.2 \pm 0.7$ & $57.0 \pm 0.6$ & $58.1 \pm 0.9$ & $54.9 \pm 1.2$ & -0.5 & -3.7 & $54.4 \pm 1.0$ & -1.4 & -6.4 \\
\hline TEamr & 40 & $51.0 \pm 0.6$ & $49.5 \pm 0.3$ & $49.5 \pm 0.3$ & $46.3 \pm 1.1$ & -9.2 & -6.5 & $51.3 \pm 0.6$ & 0.6 & 3.6 \\
\hline
\end{tabular}

LCGU values (mean \pm SD in $\mu \mathrm{mol} / 100 \mathrm{~g} / \mathrm{min}$ ) in temporal cortical areas for observation of reaching-to-grasp movements. $0 \mathrm{i}(0 \mathrm{c})$ values represent the average $\mathrm{LCGU}$ values from the three hemispheres of the 0 monkeys ipsilateral (contralateral) to the perceived forelimb. $0 \mathrm{i} / \mathrm{Cf} \%(0 \mathrm{c} / \mathrm{Cf} \%)$, percentage differences between the $0 \mathrm{i}(0 \mathrm{c})$ and the $\mathrm{Cf}$, calculated as [experimental (ipsilateral or contralateral) - control] $/ \mathrm{control} \times 100.0 \mathrm{i} / \mathrm{Cmi} \%(0 \mathrm{c} / \mathrm{Cmc} \%)$, percentage differences between the $\mathrm{Oi}(\mathrm{Oc})$ and the $\mathrm{Cmi}(\mathrm{Cmc})$, respectively. Boldface values indicate statistically significant differences by one-way ANOVA $(p<0.01)$ followed by Dunnett's post hoc test. Abbreviations are as defined in Table 3 .

MT and in area TS2 in the STG. Area PGa lying around the fundus of the STs and extending in its upper bank as well as area TAac were activated ipsilaterally to the moving forelimb, whereas areas TAar, TPOi, and TPOr were activated in the contralateral hemisphere (Table 3 ). These activations are illustrated in Figure $2 f, g$, as percentage LCGU differences of the ELi and ELc relative to the Cf monkeys, respectively. Furthermore, comparison between the EL and Cf maps revealed that the rostral part of area TEam and area TE were significantly depressed bilaterally (Table 3). No consistent interhemispheric differences were elicited in the activation of the temporal areas by execution in the light. Interestingly, both dorsal and ventral parts of area MT, which were found to be activated by action-execution compared with the Cf, were unaffected when compared with the $\mathrm{Cm}$, demonstrating the importance of using the purposeless-arm-motion control for the reaching-to-grasp experiments (Table 3 ).

To reveal the significantly affected temporal areas during observation of reaching-to-grasp movements, we compared the LCGU values in the O-maps, ipsilateral and contralateral to the perceived moving forelimb separately, with the corresponding values of the averaged Cf-map (Table 4). Increased metabolic activity was evident in all components of the motion complex, MTd, MTv, MST and FST, in all three parts (caudal, intermediate, and rostral) of the temporo-parieto-occipital association area (TPO), and in areas PGa, IPa and TS2, bilaterally. Area TAac exhibited an ipsilateral activation in the $\mathrm{O}$ monkeys, same way as in the EL monkeys, whereas areas TGsts and TS1 in the temporal gyrus of the $\mathrm{O}$ monkeys were activated only contralaterally to the perceived forelimb. Finally, areas TEam rostral and TE in the inferior temporal gyrus of the $\mathrm{O}$ monkeys were depressed similarly to the EL monkeys (Table 4). The corresponding pictorial representations of the net activations for the $\mathrm{O}$ monkeys (in percentage differences relative to the $\mathrm{Cf}$ ) are displayed in Figure 2h,i. Comparison of the LCGU values in the $\mathrm{O}$ monkeys with those in the $\mathrm{Cm}$ monkeys revealed activations in the superior temporal polysensory (STP) area (including areas TPO, PGa and IPa) similar to those described for the $\mathrm{O}$ versus $\mathrm{Cf}$ comparison. Interestingly, all components of the motion complex (including areas MTd, MTv, MST and FST) of the O monkeys were found to be activated much less when compared with the $\mathrm{Cm}$ than to the $\mathrm{Cf}$ (Table 4). No consistent interhemispheric difference was revealed in the affected MC and STP for observation relative to Cf. The smaller contralateral compared with ipsilateral activations in the MC relative to the $\mathrm{Cm}$ are due to the fact that the $\mathrm{Cm}$ itself elicits activations which are higher on the contralateral side (Raos et al., 2014).

To reveal the effects induced by reaching-to-grasp in the dark, we constructed averaged metabolic maps of the two ipsilateral and the two contralateral hemispheres of the ED monkeys separately (Fig. 3b,c), and compared them with the metabolic map obtained from averaging the three hemispheres of the two Cd monkeys (Fig. 3a). Percentage LCGU differences (net activations) between ED and Cd are illustrated in Figure 3 d,e. All the components of the motion complex were activated bilaterally, with the contralateral side displaying slightly higher activations (Table 5). At this point it should be mentioned that, although activation of the same areas in the EL, ED, and $\mathrm{O}$ monkeys reflects involvement of these areas in both the generation and observation of a reaching-to-grasp action, overlapping activations do not necessarily indicate the involvement of the very same cell populations.

The subtraction of the LCGU values in the Cf-map from the corresponding values in the EL and O maps corrects for the effects due to unspecific arousal and spot-fixation. Subtraction of the $\mathrm{Cm}$ map from the $\mathrm{El}$ and $\mathrm{O}$ maps corrects for the effects of viewing the purposeless motion of the reaching arm and the $3 \mathrm{D}$ object to be grasped, thus revealing the effects elicited by the purposeful guidance of the forelimb to reach accurately and grasp 
properly. Accordingly, to illustrate the effects induced by the purposeless motion from those elicited by the goaldirected action, we plotted the percentage LCGU differences between experimental groups and all possible corresponding control groups, i.e., between EL (O) and the $\mathrm{Cf}$, between EL $(\mathrm{O})$ and the $\mathrm{Cm}$, and between ED and the Cd. We traced two strips which started from the posterior crown of the Sylvian fissure, continued through the superior temporal gyrus and the two banks of the STs, and ended at the anterior crown of the lunate sulcus (in dorsal sections) or at the anterior crown of the inferior occipital sulcus (in ventral sections). These two strips traverse the temporal cortex at the level of the biggest recorded effects, i.e., at the level of the motion complex. More specifically, the first strip spanned areas paAlt, TAa-caudal, TPO-caudal, MST, MTd, V4t, and V4, whereas the second strip covered areas TS3, TAa-intermediate, TPO-intermediate, FST, MTv, and TEO (Fig. 4a). These strips track metabolic effects (average of the percentage LCGU-differences and 95\% confidence intervals) in the aforementioned areas, with a spatial resolution of $100 \mu \mathrm{m}$. The length of the two strips corresponds to the length of the abscissa in the graphs, with the fundus of the STs represented at point zero (0) on the abscissa (Fig. $4 b-g$ ). The ordinate indicates percentage LCGU difference from the relevant control (Fig. $4 b, c$, the Cf; $d$,e, the $\mathrm{Cm}$; and $f, g$, the $\mathrm{Cd}$ ).

If we compare the effects in the EL group relative to the $\mathrm{Cf}$ with the effects in the EL relative to the $\mathrm{Cm}$ within the dorsal cortical field (Fig. $4 b, d$, dashed and solid red lines for ipsilateral and contralateral hemispheres, respectively), we observe that area MTd is activated when the Cf is used as the control (Fig. $4 b$, red lines) and remains unaffected when the $\mathrm{Cm}$ is used as control (Fig. $4 d$, red lines). The latter findings indicate that the activation of the motion complex for action-execution is associated with the sight of the moving arm. In contrast, the marked activation of MST relative to $\mathrm{Cf}$ in the $\mathrm{O}$ group (Fig. $4 b$, solid and dashed green lines) persists, although smaller, when the $\mathrm{Cm}$ is used as the control (Fig. $4 d$, green lines). The latter finding indicates that activation of the motion complex for action-observation is only partially associated with the sight of the moving arm. Figure $4 c$,e illustrates similar effects on the ventral part of the motion complex in the EL and O groups relative to the $\mathrm{Cf}$ and $\mathrm{Cm}$, respectively. Plots of the EL effects relative to the $\mathrm{Cf}$ (solid and dashed red lines for ipsilateral and contralateral hemispheres, respectively) show increased activity in areas MTv (Fig. $4 c$ ), which drops $<0 \%$ in the El versus $\mathrm{Cm}$ plot (Fig. $4 e)$. In contrast, the marked activations of the intermediate component of TPO and of areas FST and MTv in the O group relative to the $\mathrm{Cf}$ (Fig. $4 c$, solid and dotted green lines) persist, although smaller, when the $\mathrm{Cm}$ is used as the control (Fig. 4e, green lines).
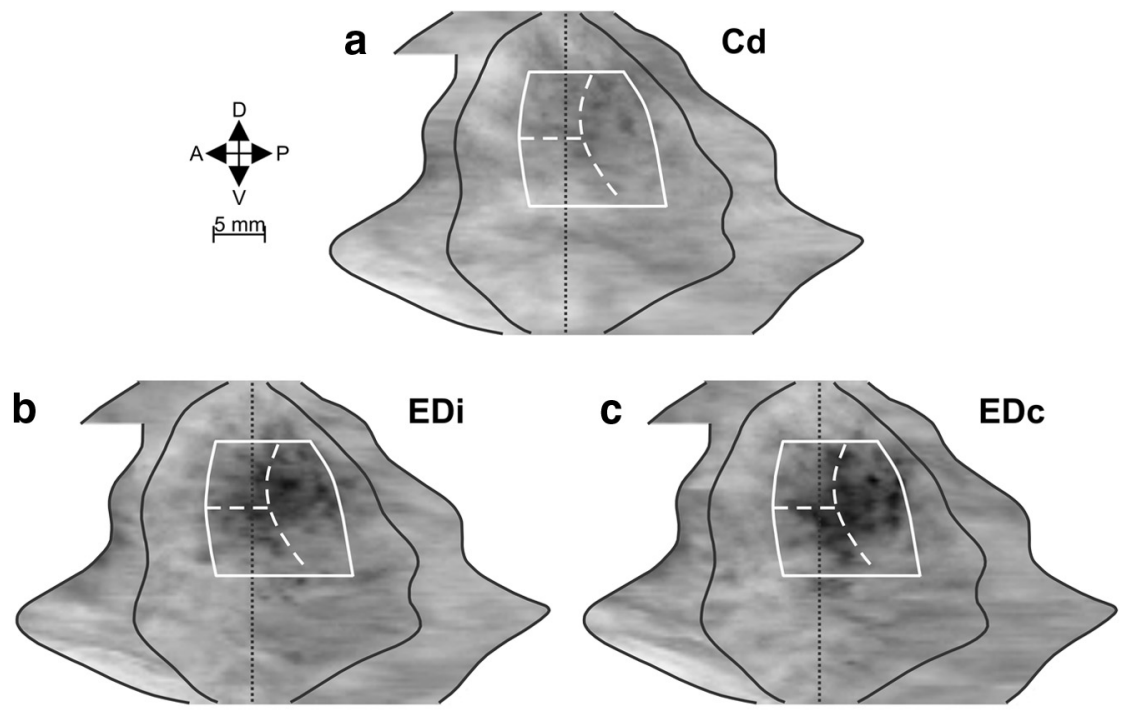

LCGU $(\mu \mathrm{mol} / 100 \mathrm{~g} / \mathrm{min})$
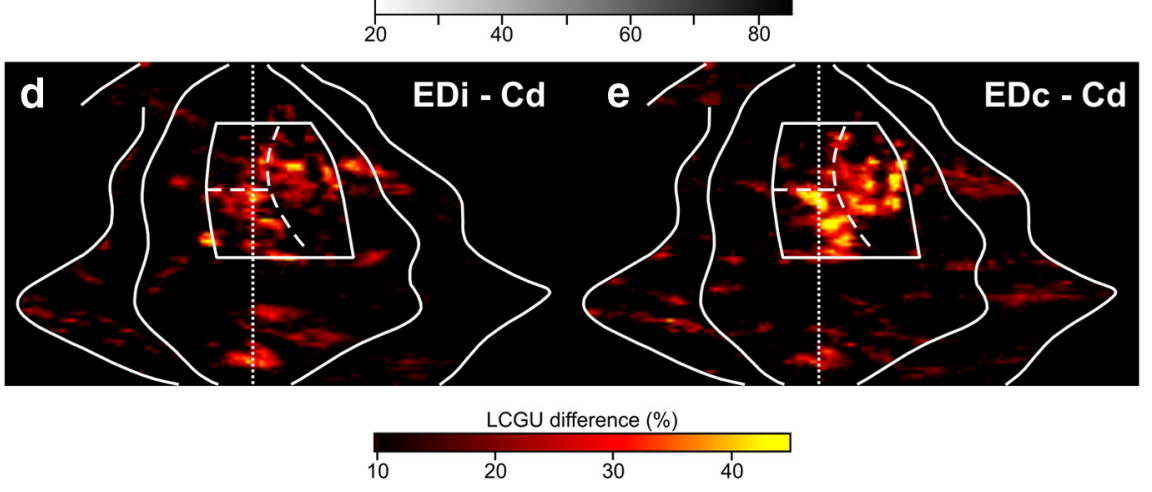

Figure 3. Quantitative 2D maps of activity in the temporal cortex of monkeys reaching-to-grasp in the dark. $\boldsymbol{a}$, Quantitative 2D map of metabolic activity obtained after averaging the LCGU values, pixel by pixel, in the geometrically normalized maps of the

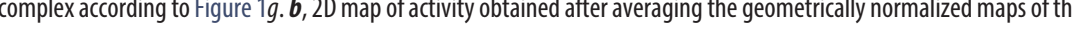
c, 2D map of activity obtained after averaging the geometrically normalized maps of the two hemispheres contralateral to the moving forelimb, in the two ED monkeys (EDC). Gray scale indicates glucose consumption (LCGU values) in $\mu \mathrm{mol} / 100 \mathrm{~g} / \mathrm{min} . \boldsymbol{d}, \boldsymbol{e}$, Quantitative 2D maps of net activations for action execution in the dark, generated after subtracting the average Cd map (shown in $\boldsymbol{a}$ ) from the average EDi and EDc maps (shown in $\boldsymbol{b}$ and c, respectively) and expressed as percentage LCGU difference. Color bar indicates percentage LCGU difference from the Cd monkey.

Finally, the plots of the effects in the ED relative to the Cd (Fig. $4 \mathrm{f}, \mathrm{g})$ demonstrate pronounced activity in all the components of the motion complex. At this point, we should mention that a few peak values evident in the graphs, such as those in area FST-ipsi (Fig. $4 e$, dashed red line) and area V4-contra (Fig. $4 b, d$, solid red lines; $f$, solid blue line), may correspond to activity confined to a small portion of the area, inadequate to elicit an overall significant result (Tables 3, 5). In other words, the high resolution of the graphical representation $(100 \mu \mathrm{m})$ is sufficient to detect activation spots within a cortical subarea, which may not be reflected in the overall effect of the entire cortical area.

Finally, to demonstrate the different pattern of effects induced in the dorsal and ventral temporal areas by the different examined conditions, we generated bar graphs illustrating the percentage differences in metabolic activation of the affected areas. Given that the pattern of effects in each and all components of the motion complex was similar, we used the average percentage 
Table 5. Metabolic effects of reaching-to-grasp in the dark

\begin{tabular}{|c|c|c|c|c|c|c|}
\hline Cortical area & $n$ & $\begin{array}{c}C d \\
(L C G U \pm S D)\end{array}$ & $\begin{array}{c}\text { Edi } \\
(\mathrm{LCGU} \pm \mathrm{SD})\end{array}$ & $\begin{array}{c}E D i / C d \\
(\%)\end{array}$ & $\begin{array}{c}\mathrm{EDC} \\
(\mathrm{LCGU} \pm \mathrm{SD})\end{array}$ & $\begin{array}{c}\mathrm{EDC} / \mathrm{Cd} \\
(\%)\end{array}$ \\
\hline MST & 63 & $52.4 \pm 1.1$ & $57.6 \pm 1.1$ & 9.9 & $56.9 \pm 1.9$ & 8.6 \\
\hline FST & 75 & $48.5 \pm 1.0$ & $56.7 \pm 1.1$ & 16.9 & $59.5 \pm 1.8$ & 22.7 \\
\hline MTd & 63 & $57.0 \pm 0.8$ & $65.7 \pm 1.3$ & 15.3 & $66.1 \pm 1.5$ & 16.0 \\
\hline MTv & 75 & $51.1 \pm 0.9$ & $55.3 \pm 1.0$ & 8.2 & $59.0 \pm 1.7$ & 15.5 \\
\hline Tpt & 71 & $41.6 \pm 0.3$ & $40.6 \pm 1.7$ & -2.4 & $43.3 \pm 1.7$ & 4.1 \\
\hline paAlt & 84 & $51.5 \pm 1.1$ & $49.5 \pm 1.8$ & -3.9 & $51.5 \pm 1.9$ & 0.0 \\
\hline TS3 & 109 & $45.9 \pm 1.1$ & $45.8 \pm 1.8$ & -0.2 & $47.2 \pm 2.1$ & 2.8 \\
\hline TS2 & 73 & $41.4 \pm 1.0$ & $40.6 \pm 1.4$ & -1.9 & $43.9 \pm 1.7$ & 6.0 \\
\hline TS1 & 94 & $34.5 \pm 1.3$ & $35.2 \pm 1.8$ & 2.0 & $34.0 \pm 2.0$ & -1.4 \\
\hline TAac & 63 & $41.6 \pm 1.3$ & $40.0 \pm 0.7$ & -3.8 & $41.3 \pm 0.9$ & -0.7 \\
\hline TAai & 75 & $49.5 \pm 0.4$ & $45.5 \pm 0.5$ & -8.1 & $48.0 \pm 0.7$ & -3.0 \\
\hline TAar & 90 & $42.7 \pm 0.7$ & $41.9 \pm 0.9$ & -1.9 & $44.1 \pm 0.7$ & 3.3 \\
\hline TPOC & 63 & $44.3 \pm 0.8$ & $45.5 \pm 1.3$ & 2.7 & $43.7 \pm 1.1$ & -1.4 \\
\hline TPOi & 75 & $45.7 \pm 0.8$ & $44.9 \pm 1.6$ & -1.8 & $47.1 \pm 0.6$ & 3.1 \\
\hline TPOr & 35 & $42.7 \pm 1.0$ & $41.9 \pm 0.6$ & -1.9 & $41.1 \pm 0.8$ & -3.7 \\
\hline PGa & 53 & $46.0 \pm 0.6$ & $47.0 \pm 1.2$ & 2.2 & $45.5 \pm 0.8$ & -1.1 \\
\hline $\mathrm{IPa}$ & 44 & $49.1 \pm 0.8$ & $51.6 \pm 0.7$ & 5.1 & $49.7 \pm 1.3$ & 1.2 \\
\hline TGsts & 40 & $39.2 \pm 0.4$ & $41.8 \pm 1.0$ & 6.6 & $41.6 \pm 0.9$ & 6.1 \\
\hline V4 & 80 & $48.1 \pm 1.6$ & $45.9 \pm 1.5$ & -4.6 & $50.1 \pm 1.5$ & 4.2 \\
\hline V4t & 80 & $48.9 \pm 1.1$ & $52.1 \pm 1.6$ & 6.5 & $52.0 \pm 1.5$ & 6.3 \\
\hline TEO & 129 & $44.0 \pm 1.3$ & $43.9 \pm 2.0$ & -0.2 & $46.4 \pm 1.4$ & 5.5 \\
\hline TE & 141 & $44.3 \pm 0.7$ & $43.4 \pm 0.8$ & -2.0 & $46.5 \pm 1.0$ & 5.0 \\
\hline TEamc & 91 & $48.7 \pm 0.6$ & $49.4 \pm 1.1$ & 1.4 & $49.8 \pm 0.6$ & 2.3 \\
\hline TEamr & 40 & $43.4 \pm 0.8$ & $45.8 \pm 1.3$ & 5.5 & $45.9 \pm 1.2$ & 5.8 \\
\hline
\end{tabular}

LCGU values (mean \pm SD in $\mu \mathrm{mol} / 100 \mathrm{~g} / \mathrm{min}$ ) in temporal cortical areas of the monkey brain for execution of reaching-to-grasp in the dark (ED). C d values represent the average $L C G U$ values from the three control hemispheres of the control monkeys in the dark. $E D i(E D c)$ values represent the average $L C G U$ values from the two hemispheres of the ED monkeys ipsilateral (contralateral) to the moving forelimb. EDi/Cd\% (EDc/Cd\%), percentage differences between the EDi (EDc) and the $(d$, calculated as [experimental (ipsilateral or contralateral) - control]/control $\times$ 100. Boldface values indicate statistically significant differences by one-way ANOVA $(p<0.01)$ followed by Dunnett's post hoc test. Abbreviations are as defined in Table 3.

difference in MTd, MTv, MST, and FST to generate each bar graph for the MC (Fig. 5a). In this figure, the Cm, the EL, and the $\mathrm{O}$ bar graphs represent percentage differences relative to the $\mathrm{Cf}$, whereas the ED bar graph represents differences relative to the $\mathrm{Cd}$. In a similar way, we generated bar graphs demonstrating the pattern of effects in the STP, using the average percentage difference of metabolic activations in areas TPOr, PGa, and IPa (Fig. 5b).

\section{Discussion}

The present study is the first to provide high-resolution quantitative functional maps of the temporal cortex of monkeys engaged in execution of reaching-to-grasp movements either in the light or in the dark, and in observation of the same movements performed by another agent. We demonstrate that specific temporal cortical areas support goal-directed actions, and we resolve the unsettled issue whether the motion complex is implicated in action-execution and/or action-observation.

\section{Dorsal temporal areas}

The motion-sensitive visual areas MT/V5, MST, and FST exhibited increased metabolic activity for observation of reaching-tograsp. However, Figure 4 illustrates that these activations in the motion complex were much smaller compared with the $\mathrm{Cm}$ than the Cf, indicating that the effect was associated partly with the perception of biological motion (arm-motion) and partly with the observation of goal-directed reaching-to-grasp. Our findings are consistent with those of previous neuroimaging studies in humans suggesting that the STs and adjacent cortex is involved in the observation of goal-directed actions (Iacoboni et al., 2001; Perani et al., 2001; Pierno et al., 2006; Gazzola et al., 2007; Turella et al., 2009; Biagi et al., 2010). However, unlike our study these reports of lower spatial resolution in humans do not allow for attribution of the detected activations to specific anatomical regions.

Interestingly, only area MT among the components of the motion complex displayed increased activity for execution of reaching-to-grasp in the light, and this only when compared with the Cf. The motion complex remained unaffected by visually guided action-execution when compared with the $\mathrm{Cm}$. Therefore, the use of the motion-control monkeys allowed us to disambiguate the effects associated with viewing the object and the moving upper limb from the effects related to the purposeful reaching, hand shaping and grasping. The lack of MT-activation in monkeys performing in the light as compared with the $\mathrm{Cm}$ implies that this activation results from the view of the armmotion rather than by the movement per se. However, the possibility cannot be excluded that an underlying activation of MT is hidden by an inhibitory efference copy due to self-execution. Our results are compatible with those of Oreja-Guevara et al. (2004) who reported lack of activation in hMT + during the execution of purposeful ballistic arm-movements compared with a motion control. Moreover, the contribution of the temporal cortex to action-execution, based on results of studies using only static pictures as a control (Iacoboni et al., 2001; Oosterhof et al., 2010), should be reconsidered. Finally, our finding that area MT is not involved in movement execution per se is supported by neurophysiological recordings demonstrating that MT neurons do not display any motor properties (Keysers and Perrett, 2004; Dannenberg et al., 2009).

Surprisingly, areas MT, MST, and FST exhibited increased metabolic activity for execution of reaching-to-grasp in complete darkness. This finding is in agreement with the results of a previous neuroimaging study reporting activations in the temporal cortex of humans who were performing reaching-to-grasp actions invisible to the performer (Gazzola and Keysers, 2009). Given that the action was executed in complete darkness, the activation of motion complex can be associated neither with the sight of arm-motion nor with the visual guidance of movements. One could argue that this activation is associated with the only variable kept fixed, i.e., the execution of movements per se. In fact, this suggestion would be compatible with the report that a transient lesion of MST produced pointing errors in reaching movements toward previously seen targets (Ilg and Schumann, 2007). However, no motor properties have been recorded in any cells of the motion complex to date, as already mentioned, and also activation of area MT is associated with the sight of the moving arm and not with the movement itself according to our present findings. Thus, the question rises whether there are other variables that could account for the activation of the motion complex during action-execution in the dark. Indeed, to act efficiently the blindfolded actor has to mentally recall the lacking visual information concerning the location of the object to be grasped and the precise arm/hand movement for successful reaching-to-grasp.

We have previously suggested that the activation of early visual cortices (V1, V2, and V3d) for action-generation in complete darkness reflects an internal visual portrayal of the invisible/ memorized object to be grasped and of the invisible arm moving within the unseen spatial surrounding; in other words, it implies visual imagery from the actor's point of view (Savaki, 2010; Kilintari et al., 2011). Considering our previous and present results we suggest that the visual imagery, which may take place during action in the dark and account for the motion complex activation at present, may rely on top-down efferent signals from the fron- 


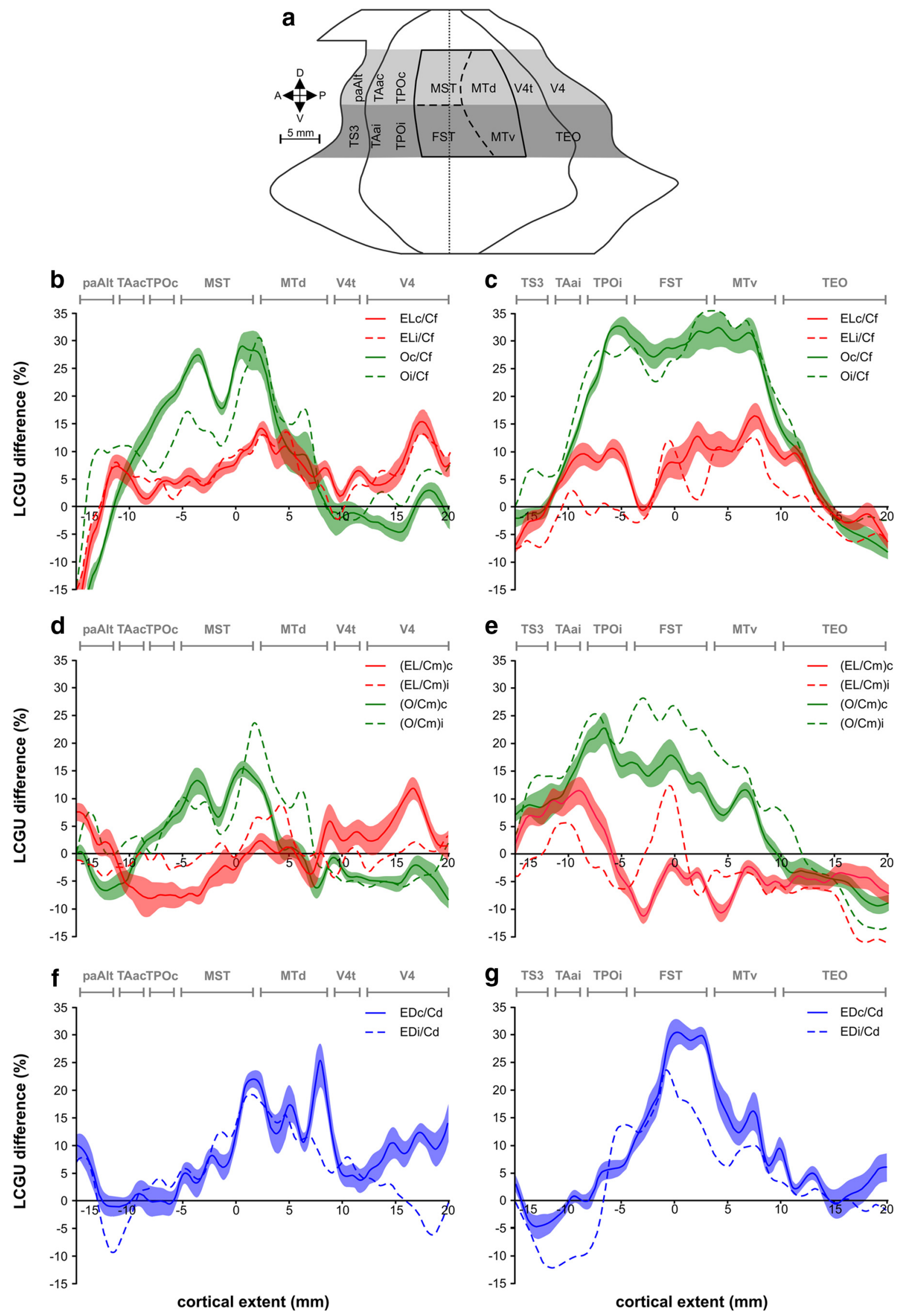

Figure 4. Plots of percentage LCGU differences between experimental and control groups at the level of the motion complex. $\boldsymbol{a}$, Illustration of two strips (in 2 different gray shades) traversing the temporal cortex at the level of the biggest recorded effects, i.e., at the level of the motion complex. These strips track metabolic effects (average of the percentage LCGU-differences from corresponding controls, and $95 \%$ confidence intervals) in the temporal areas they go through, with a spatial resolution of $100 \mu \mathrm{m}$. More specifically, (Figure legend continues.) 


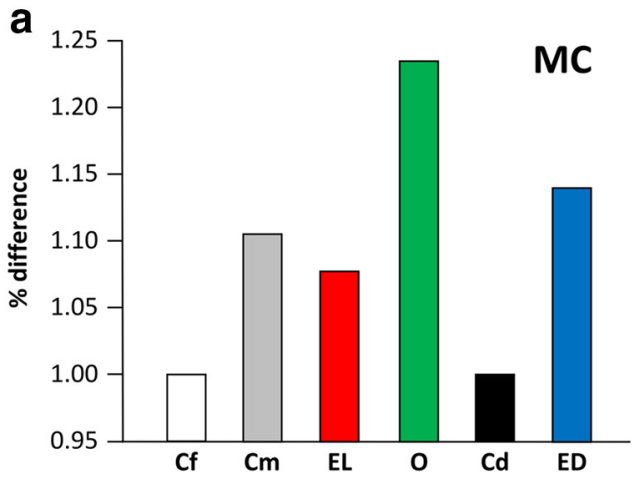

b

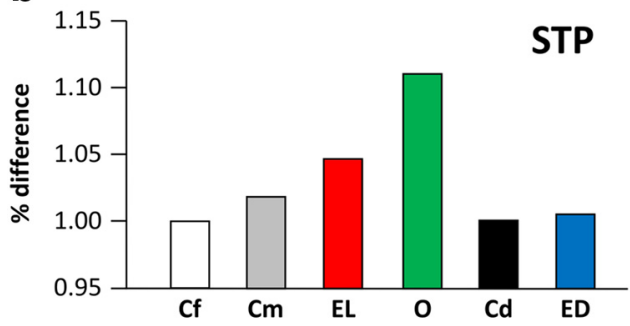

Figure 5. Bar graphs illustrating the different pattern of effects in the dorsal and ventral temporal areas. $\boldsymbol{a}$, Percentage differences in the MC (including MT, MST and FST) of (1) the motion-control group ( $\mathrm{Cm}$, gray bar), the execution-in-light condition (EL, red bar), and the observation condition ( 0 , green bar) relative to the fixation-control ( $\mathrm{Cf}$, white bar); and of (2) the execution-in-dark condition (ED, gray bar) relative to the (d (black bar). $\boldsymbol{b}$, Percentage differences in area STP (including TPOr, PGa, and IPa) of the $\mathrm{Cm}$, EL, and 0 conditions relative to the $\mathrm{Cf}$, and of the ED condition relative to the Cd. Color coding of bars as in $\boldsymbol{a}$.

toparietal system (shown to be activated in our studies; (Raos et al., 2007; Evangeliou et al., 2009) to higher order visual cortices, which may trigger the retrieval of visual representations of action stored in the dorsal visual stream. Interestingly, Keysers and Perrett (2004)made the prediction that Hebbian learning would lead to the retrieval of STS representations of actions during execution, based on the theory that events which systematically follow each other could be associated in Hebbian ways across modalities. Presumably, visual effects are interwoven with motor commands in integrated action codes. Parenthetically, when we use

$\leftarrow$

(Figure legend continued.) the dorsal strip (light gray) starts from the posterior crown of the Sf, continues through the superior temporal gyrus and the two banks of the STs, and ends at the anterior crown of the Ls, spanning areas paAlt, TAa-caudal, TPO-caudal, MST, MTd, V4t, and V4. The ventral strip, which ends at the anterior crown of the 10s, covers areas TS3, TAaintermediate, TP0-intermediate, FST, MTV, and TEO. Solid gray and black lines correspond to surface landmarks and anatomical borders respectively. Dotted black line, STs-fundus. Dashed black lines, borders of the components of the motion complex according to Figure $1 g . \boldsymbol{b}$, Plots of the percentage LCGU difference between the EL (lines in red) or the 0 (lines in green) and the Cf hemispheres in the areas covered by the dorsal strip. Solid and dashed lines represent percentage (\%) LCGU differences obtained from the contralateral and ipsilateral hemispheres, respectively. Shaded areas around the lines indicate $95 \%$ confidence intervals. The fundus of the STs is represented at point zero (0) on the abscissa. The extent of areas paAlt, TAa-caudal, TPO-caudal, MST, MTd, V4t, and V4 is indicated in bracketed lines above the graph and reflected in $\mathrm{mm}$ on the abscissa. The ordinate indicates percentage LCGU difference from the Cf. c, Plots of the percentage LCGU difference between the EL (lines in red) or the 0 (lines in green) and the Cf hemispheres in the areas covered by the ventral strip. The extent of areas TS3, TAaintermediate, TPO-intermediate, FST, MTV, and TEO is indicated in bracketed lines above the graph. Conventions as in $\boldsymbol{b}$. $\boldsymbol{d}, \boldsymbol{e}$, Plots of the percentage LCGU difference between the EL (lines in red) or the 0 (lines in green) and the $\mathrm{Cm}$ hemispheres, in the areas covered by the dorsal and ventral strip, respectively. Conventions as in $\boldsymbol{b}$. $\boldsymbol{f}, \boldsymbol{g}$, Plots of the percentage LCGU difference between the ED (lines in blue) and the $C d$ hemispheres, in the areas covered by the dorsal and ventral strip, respectively. Conventions as in $\boldsymbol{b}$. the term mental recall or visual imagery we refer to the retrieval of memorized/internal representations of an act, which is not necessarily a conscious process.

Similarly, the activation of the motion complex for graspingobservation may reflect (1) increased visual attention to the moving arm of the external actor, because the purposeful movement is not under the somatosensory control of the observer, and (2) internal/covert rehearsal (mental simulation) of the action by the onlooker. The latter suggestion is in accordance with all our previous findings (Raos et al., 2004, 2007; Evangeliou et al., 2009; Kilintari et al., 2011) which support the mental simulation theory, implying that we understand the behavior of other agents by using our own neural processes to simulate their mental states (Savaki, 2010). Further support to our suggestions about mental recall and simulation of actions is provided by studies demonstrating that areas MT/MST do not respond only to real visual motion stimuli but are also active when subjects simply imagine such stimuli (Goebel et al., 1998), and when subjects see static images of implied animate or inanimate motion (Kourtzi and Kanwisher, 2000). Likewise, activation of hMT + was reported even when motion information was conveyed via linguistic description (Tettamanti et al., 2005; Saygin et al., 2010), apparently mobilizing a mental representation of the described action. Incidentally, we should mention that the relation of our findings to those of other studies is not immediate given the differences in methodologies related to the spatial resolution and anatomical definitions as well as the task parameters.

\section{Ventral temporal areas}

The STP, which encompasses regions TPO, PGa and IPa, has long been implicated in the integration of different sensory modalities (Benevento et al., 1977; Seltzer and Pandya, 1978, 1989; Baylis et al., 1987; Boussaoud et al., 1990; Mistlin and Perrett, 1990). Its activation for action-observation but only partially/marginally for action-execution in our study is in accordance with the neurophysiological results of Perrett's group, who demonstrated the involvement of STSa/STP neurons in the perception of movements made by other subjects' body parts rather than by the monkey's own hand (Perrett et al., 1985, 1989; Hietanen and Perrett, 1993; Wachsmuth et al., 1994; Jellema et al., 2000; Keysers and Perrett, 2004). Our results are also in agreement with the report that areas LST and STPm, which correspond at least partially to areas $\mathrm{PGa} / \mathrm{IPa}$ and TPOi in our study, are activated for action-observation (Nelissen et al., 2006, 2011). Moreover, our finding that no STP-component is activated for action-execution in complete darkness is in accordance with the report that STs neurons do not respond to limb movements in the absence of visual input (Keysers and Perrett, 2004).

Activation of areas TS1/TS2, which are components of the auditory belt (Pandya and Sanides, 1973; Pandya, 1995; Poremba et al., 2003; Fullerton and Pandya, 2007), is not surprising given their multimodal association function (Pandya, 1995). In fact, the auditory association cortex receives visual, and somatosensory inputs (Schroeder et al., 2001; Schroeder and Foxe, 2002) and exhibits audio-motor association responses (Vaadia et al., 1982; Durif et al., 2003). Its activation is compatible with the report that grasping and touching events coupled with auditory input enhance neuronal discharge (Brosch et al., 2005). The sound of the opening window of the behavioral apparatus in our experiments, not informative on its own, may form a meaningful association with the sight of the moving forelimb, thus activating the auditory association cortex. 
Contrariwise, areas TE and TEamr were depressed for actionobservation and action-execution in the light. Area TE, which responds primarily to visual stimuli (Desimone and Gross, 1979; Baylis et al., 1987), is part of the occipitotemporal pathway supporting object recognition (Gross et al., 1972; Schwartz et al., 1983; Desimone et al., 1984). Similarly, areas TEa/TEm are considered unimodal visual association areas (Seltzer and Pandya, 1978; Baylis et al., 1987; Seltzer and Pandya, 1989) responding to stationary rather than moving visual stimuli (Baylis et al., 1987). The unimodal character and the stimulus selectivity of these areas could explain their depression in the EL and O conditions, when visual guidance of the moving arm is more important than object properties.

Conclusively, observation of others' actions and lack of visibility of our own actions have profound effect on the motion complex. In addition, specific STP-regions code the actions made by others but not the visual effects of our own actions. Our previous and present results together suggest that the motor cognitive processes involved in action-recognition and actionexecution in the dark may require a reciprocal dialogue between specific sets of neurons in higher-order visual areas of the temporal lobe and the parietofrontal network.

\section{References}

Bakola S, Gregoriou GG, Moschovakis AK, Raos V, Savaki HE (2007) Saccade-related information in the superior temporal motion complex: quantitative functional mapping in the monkey. J Neurosci 27:22242229. CrossRef Medline

Baylis GC, Rolls ET, Leonard CM (1987) Functional subdivisions of the temporal lobe neocortex. J Neurosci 7:330-342. Medline

Benevento LA, Fallon J, Davis BJ, Rezak M (1977) Auditory-visual interaction in single cells in the cortex of the superior temporal sulcus and the orbital frontal cortex of the macaque monkey. Exp Neurol 57:849-872. CrossRef Medline

Biagi L, Cioni G, Fogassi L, Guzzetta A, Tosetti M (2010) Anterior intraparietal cortex codes complexity of observed hand movements. Brain Res Bull 81:434-440. CrossRef Medline

Boussaoud D, Ungerleider LG, Desimone R (1990) Pathways for motion analysis: cortical connections of the medial superior temporal and fundus of the superior temporal visual areas in the macaque. J Comp Neurol 296:462-495. CrossRef Medline

Brosch M, Selezneva E, Scheich H (2005) Nonauditory events of a behavioral procedure activate auditory cortex of highly trained monkeys. J Neurosci 25:6797-6806. CrossRef Medline

Bruce CJ, Goldberg ME (1985) Primate frontal eye fields: I. Single neurons discharging before saccades. J Neurophysiol 53:603-635. Medline

Buccino G, Binkofski F, Fink GR, Fadiga L, Fogassi L, Gallese V, Seitz RJ, Zilles K, Rizzolatti G, Freund HJ (2001) Action observation activates premotor and parietal areas in a somatotopic manner: an fMRI study. Eur J Neurosci 13:400-404. CrossRef Medline

Dalezios Y, Raos VC, Savaki HE (1996) Metabolic activity pattern in the motor and somatosensory cortex of monkeys performing a visually guided reaching task with one forelimb. Neuroscience 72:325-333. CrossRef Medline

Dannenberg S, Gieselmann MA, Kruse W, Hoffmann KP (2009) Influence of visually guided tracking arm movements on single cell activity in area MT. Exp Brain Res 199:355-368. CrossRef Medline

Desimone R, Gross CG (1979) Visual areas in the temporal cortex of the macaque. Brain Res 178:363-380. CrossRef Medline

Desimone R, Ungerleider LG (1986) Multiple visual areas in the caudal superior temporal sulcus of the macaque. J Comp Neurol 248:164-189. CrossRef Medline

Desimone R, Albright TD, Gross CG, Bruce C (1984) Stimulus-selective properties of inferior temporal neurons in the macaque. J Neurosci 4:2051-2062. Medline

Durif C, Jouffrais C, Rouiller EM (2003) Single-unit responses in the auditory cortex of monkeys performing a conditional acousticomotor task. Exp Brain Res 153:614-627. CrossRef Medline

Evangeliou MN, Raos V, Galletti C, Savaki HE (2009) Functional imaging of the parietal cortex during action execution and observation. Cereb Cortex 19:624-639. CrossRef Medline

Fullerton BC, Pandya DN (2007) Architectonic analysis of the auditoryrelated areas of the superior temporal region in human brain. J Comp Neurol 504:470-498. CrossRef Medline

Gazzola V, Keysers C (2009) The observation and execution of actions share motor and somatosensory voxels in all tested subjects: single-subject analyses of unsmoothed fMRI data. Cereb Cortex 19:1239-1255. CrossRef Medline

Gazzola V, Rizzolatti G, Wicker B, Keysers C (2007) The anthropomorphic brain: the mirror neuron system responds to human and robotic actions. Neuroimage 35:1674-1684. CrossRef Medline

Goebel R, Khorram-Sefat D, Muckli L, Hacker H, Singer W (1998) The constructive nature of vision: direct evidence from functional magnetic resonance imaging studies of apparent motion and motion imagery. Eur J Neurosci 10:1563-1573. CrossRef Medline

Gregoriou GG, Savaki HE (2003) When vision guides movement: a functional imaging study of the monkey brain. Neuroimage 19:959-967. CrossRef Medline

Grosbras MH, Paus T (2006) Brain networks involved in viewing angry hands or faces. Cereb Cortex 16:1087-1096. CrossRef Medline

Gross CG, Rocha-Miranda CE, Bender DB (1972) Visual properties of neurons in inferotemporal cortex of the macaque. J Neurophysiol 35:96-111. Medline

Hietanen JK, Perrett DI (1993) Motion sensitive cells in the macaque superior temporal polysensory area: I. Lack of response to the sight of the animals own limb movement. Exp Brain Res 93:117-128. Medline

Hof PR, Morrison JH (1995) Neurofilament protein defines regional patterns of cortical organization in the macaque monkey visual system: a quantitative immunohistochemical analysis. J Comp Neurol 352:161186. CrossRef Medline

Iacoboni M, Koski LM, Brass M, Bekkering H, Woods RP, Dubeau MC, Mazziotta JC, Rizzolatti G (2001) Reafferent copies of imitated actions in the right superior temporal cortex. Proc Natl Acad Sci U S A 98:1399513999. CrossRef Medline

Ilg UJ, Schumann S (2007) Primate area MST-l is involved in the generation of goal-directed eye and hand movements. J Neurophysiol 97:761-771. CrossRef Medline

Jellema T, Baker CI, Wicker B, Perrett DI (2000) Neural representation for the perception of the intentionality of actions. Brain Cogn 44:280-302. CrossRef Medline

Kennedy C, Sakurada O, Shinohara M, Jehle J, Sokoloff L (1978) Local cerebral glucose utilization in the normal conscious macaque monkey. Ann Neurol 4:293-301. CrossRef Medline

Keysers C, Perrett DI (2004) Demystifying social cognition: a Hebbian perspective. Trends Cogn Sci 8:501-507. CrossRef Medline

Kilintari M, Raos V, Savaki HE (2011) Grasping in the dark activates early visual cortices. Cereb Cortex 21:949-963. CrossRef Medline

Kourtzi Z, Kanwisher N (2000) Activation in human MT/MST by static images with implied motion. J Cogn Neurosci 12:48-55. CrossRef Medline

Maunsell JH, Van Essen DC (1983) Functional properties of neurons in middle temporal visual area of the macaque monkey: I. Selectivity for stimulus direction, speed, and orientation. J Neurophysiol 49:1127-1147. Medline

Mistlin AJ, Perrett DI (1990) Visual and somatosensory processing in the macaque temporal cortex: the role of "expectation". Exp Brain Res 82: 437-450. Medline

Moschovakis AK, Gregoriou GG, Ugolini G, Doldan M, Graf W, Guldin W, Hadjidimitrakis K, Savaki HE (2004) Oculomotor areas of the primate frontal lobes: a transneuronal transfer of rabies virus and ${ }^{14} \mathrm{C}-2$ deoxyglucose functional imaging study. J Neurosci 24:5726-5740. CrossRef Medline

Nedelko V, Hassa T, Hamzei F, Weiller C, Binkofski F, Schoenfeld MA, Tüscher O, Dettmers C (2010) Age-independent activation in areas of the mirror neuron system during action observation and action imagery: a fMRI study. Restor Neurol Neurosci 28:737-747. CrossRef Medline

Nelissen K, Vanduffel W, Orban GA (2006) Charting the lower superior temporal region, a new motion-sensitive region in monkey superior temporal sulcus. J Neurosci 26:5929-5947. CrossRef Medline

Nelissen K, Borra E, Gerbella M, Rozzi S, Luppino G, Vanduffel W, Rizzolatti 
G, Orban GA (2011) Action observation circuits in the macaque monkey cortex. J Neurosci 31:3743-3756. CrossRef Medline

Ohnishi T, Moriguchi Y, Matsuda H, Mori T, Hirakata M, Imabayashi E, Hirao K, Nemoto K, Kaga M, Inagaki M, Yamada M, Uno A (2004) The neural network for the mirror system and mentalizing in normally developed children: an fMRI study. Neuroreport 15:1483-1487. CrossRef Medline

Oosterhof NN, Wiggett AJ, Diedrichsen J, Tipper SP, Downing PE (2010) Surface-based information mapping reveals crossmodal vision-action representations in human parietal and occipitotemporal cortex. J Neurophysiol 104:1077-1089. CrossRef Medline

Oram MW, Perrett DI (1994) Responses of anterior superior temporal polysensory (STPa) neurons to "biological motion" stimuli. J Cogn Neurosci 6:99-116. CrossRef Medline

Oreja-Guevara C, Kleiser R, Paulus W, Kruse W, Seitz RJ, Hoffmann KP (2004) The role of V5 (hMT+) in visually guided hand movements: an fMRI study. Eur J Neurosci 19:3113-3120. CrossRef Medline

Pandya DN (1995) Anatomy of the auditory cortex. Rev Neurol (Paris) 151: 486-494. Medline

Pandya DN, Sanides F (1973) Architectonic parcellation of the temporal operculum in rhesus monkey and its projection pattern. Z Anat Entwicklungsgesch 139:127-161. CrossRef Medline

Perani D, Fazio F, Borghese NA, Tettamanti M, Ferrari S, Decety J, Gilardi MC (2001) Different brain correlates for watching real and virtual hand actions. Neuroimage 14:749-758. CrossRef Medline

Perrett DI, Smith PA, Mistlin AJ, Chitty AJ, Head AS, Potter DD, Broennimann R, Milner AD, Jeeves MA (1985) Visual analysis of body movements by neurones in the temporal cortex of the macaque monkey: a preliminary report. Behav Brain Res 16:153-170. Medline

Perrett DI, Harries MH, Bevan R, Thomas S, Benson PJ, Mistlin AJ, Chitty AJ, Hietanen JK, Ortega JE (1989) Frameworks of analysis for the neural representation of animate objects and actions. J Exp Biol 146:87-113. Medline

Petrides M, Pandya DN (2006) Efferent association pathways originating in the caudal prefrontal cortex in the macaque monkey. J Comp Neurol 498:227-251. CrossRef Medline

Pierno AC, Becchio C, Wall MB, Smith AT, Castiello U (2006) Transfer of interfered motor patterns to self from others. Eur J Neurosci 23:19491955. CrossRef Medline

Poremba A, Saunders RC, Crane AM, Cook M, Sokoloff L, Mishkin M (2003) Functional mapping of the primate auditory system. Science 299: 568-572. CrossRef Medline

Raos V, Evangeliou MN, Savaki HE (2004) Observation of action: grasping with the mind's hand. Neuroimage 23:193-201. CrossRef Medline

Raos V, Evangeliou MN, Savaki HE (2007) Mental simulation of action in the service of action perception. J Neurosci 27:12675-12683. CrossRef Medline

Raos V, Kilintari M, Savaki HE (2014) Viewing a forelimb induces widespread cortical activations. Neuroimage 89:122-142. CrossRef Medline

Rizzolatti G, Craighero L (2004) The mirror-neuron system. Annu Rev Neurosci 27:169-192. CrossRef Medline

Rizzolatti G, Fadiga L, Matelli M, Bettinardi V, Paulesu E, Perani D, Fazio F (1996) Localization of grasp representations in humans by PET: 1. Observation versus execution. Exp Brain Res 111:246-252. Medline

Rizzolatti G, Fogassi L, Gallese V (2001) Neurophysiological mechanisms underlying the understanding and imitation of action. Nat Rev Neurosci 2:661-670. CrossRef Medline

Robinson DA, Fuchs AF (1969) Eye movements evoked by stimulation of frontal eye fields. J Neurophysiol 32:637-648. Medline

Saleem K, Logothetis N (2007) A combined MRI and histology atlas of the rhesus monkey brain in stereotaxic coordinates. London, UK: Academic.

Savaki HE (2010) How do we understand the actions of others? By mental simulation, NOT mirroring. Cogn Critique 2:99-140.

Savaki HE, Dalezios Y (1999) ${ }^{14} \mathrm{C}$-deoxyglucose mapping of the monkey brain during reaching to visual targets. Prog Neurobiol 58:473-540. CrossRef Medline

Savaki HE, Kennedy C, Sokoloff L, Mishkin M (1993) Visually guided reaching with the forelimb contralateral to a "blind" hemisphere: a metabolic mapping study in monkeys. J Neurosci 13:2772-2789. Medline

Savaki HE, Raos VC, Dalezios Y (1997) Spatial cortical patterns of metabolic activity in monkeys performing a visually guided reaching task with one forelimb. Neuroscience 76:1007-1034. CrossRef Medline

Savaki HE, Gregoriou GG, Bakola S, Raos V, Moschovakis AK (2010) The place code of saccade metrics in the lateral bank of the intraparietal sulcus. J Neurosci 30:1118-1127. CrossRef Medline

Savaki HE, Gregoriou GG, Bakola S, Moschovakis AK (2014) Topography of visuomotor parameters in the frontal and premotor eye fields. Cereb Cortex, in press. CrossRef Medline

Saygin AP, McCullough S, Alac M, Emmorey K (2010) Modulation of BOLD response in motion-sensitive lateral temporal cortex by real and fictive motion sentences. J Cogn Neurosci 22:2480-2490. CrossRef Medline

Schroeder CE, Foxe JJ (2002) The timing and laminar profile of converging inputs to multisensory areas of the macaque neocortex. Brain Res Cogn Brain Res 14:187-198. CrossRef Medline

Schroeder CE, Lindsley RW, Specht C, Marcovici A, Smiley JF, Javitt DC (2001) Somatosensory input to auditory association cortex in the macaque monkey. J Neurophysiol 85:1322-1327. Medline

Schwartz EL, Desimone R, Albright TD, Gross CG (1983) Shape recognition and inferior temporal neurons. Proc Natl Acad Sci U S A 80:5776-5778. CrossRef Medline

Seltzer B, Pandya DN (1978) Afferent cortical connections and architectonics of the superior temporal sulcus and surrounding cortex in the rhesus monkey. Brain Res 149:1-24. CrossRef Medline

Seltzer B, Pandya DN (1989) Intrinsic connections and architectonics of the superior temporal sulcus in the macaque monkey. J Comp Neurol 290: 451-471. CrossRef Medline

Shmuelof L, Zohary E (2005) Dissociation between ventral and dorsal fMRI activation during object and action recognition. Neuron 47:457-470. CrossRef Medline

Shmuelof L, Zohary E (2006) A mirror representation of others' actions in the human anterior parietal cortex. J Neurosci 26:9736-9742. CrossRef Medline

Sokoloff L, Reivich M, Kennedy C, Des Rosiers MH, Patlak CS, Pettigrew KS, Sakurada O, Shinohara M (1977) The ${ }^{14} \mathrm{C}$-deoxyglucose method for the measurement of local cerebral glugose utilization: theory, procedure, and normal values in the conscious and anesthetized albino rat. J Neurochem 28:879-916. Medline

Tai YF, Scherfler C, Brooks DJ, Sawamoto N, Castiello U (2004) The human premotor cortex is "mirror" only for biological actions. Curr Biol 14:117120. CrossRef Medline

Tettamanti M, Buccino G, Saccuman MC, Gallese V, Danna M, Scifo P, Fazio F, Rizzolatti G, Cappa SF, Perani D (2005) Listening to action-related sentences activates fronto-parietal motor circuits. J Cogn Neurosci 17: 273-281. CrossRef Medline

Turella L, Erb M, Grodd W, Castiello U (2009) Visual features of an observed agent do not modulate human brain activity during action observation. Neuroimage 46:844-853. CrossRef Medline

Vaadia E, Gottlieb Y, Abeles M (1982) Single-unit activity related to sensorimotor association in auditory cortex of a monkey. J Neurophysiol 48: 1201-1213. Medline

Wachsmuth E, Oram MW, Perrett DI (1994) Recognition of objects and their component parts: responses of single units in the temporal cortex of the macaque. Cereb Cortex 4:509-522. CrossRef Medline

Zeki SM (1974) Functional organization of a visual area in the posterior bank of the superior temporal sulcus of the rhesus monkey. J Physiol 236:549-573. Medline 